Instrumentation and Controls Division

FINAL REPORT

\title{
GUIDANCE FOR THE DESIGN AND MANAGEMENT OF A MAINTENANCE PLAN TO ASSURE SAFETY AND IMPROVE THE PREDICTABILITY OF A DOE NUCLEAR IRRADIATION FACILITY
}

\author{
Contributors \\ R. S. Booth1, R. C. Kryter, W. J. Rowan'2, R. L. Shepard, O. L. Smith, \\ and B. R. Upadhyaya ${ }^{3}$ \\ Reviewers \\ R. L. Clark and J. A. Mullens \\ Program Manager \\ R. L. Shepard
}

Date Published—October 1994

Prepared for the

U.S. Department of Energy

Office of Nuclear Safety Self-Assessment

\author{
Prepared by \\ OAK RIDGE NATIONAL LABORATORY \\ Oak Ridge, Tennessee 37831-6285 \\ managed by \\ MARTIN MARIETTA ENERGY SYSTEMS, INC. \\ for the \\ U.S. DEPARTMENT OF ENERGY \\ under contract DE-AC05-84OR21400
}

\begin{abstract}
NOTICE This document contains information of a preliminary nature. It is subject to revision or correction and therefore does not represent a final report.
\end{abstract}

1 Engineering Division.

2 Consultant.

3 Department of Nuclear Engineering, The University of Tennessee, Knoxville.

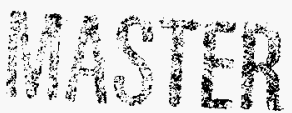




\section{DISCLAIMER}

This report was prepared as an account of work sponsored by an agency of the United States Government. Neither the United States Government nor any agency thereof, nor any of their employees, make any warranty, express or implied, or assumes any legal liability or responsibility for the accuracy, completeness, or usefulness of any information, apparatus, product, or process disclosed, or represents that its use would not infringe privately owned rights. Reference herein to any specific commercial product, process, or service by trade name, trademark, manufacturer, or otherwise does not necessarily constitute or imply its endorsement, recommendation, or favoring by the United States Government or any agency thereof. The views and opinions of authors expressed herein do not necessarily state or reflect those of the United States Government or any agency thereof. 


\section{DISCLAIMER}

Portions of this document may be illegible in electronic image products. Images are produced from the best available original document. 


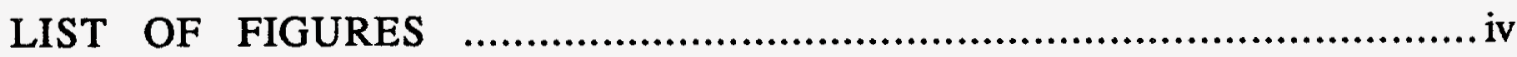

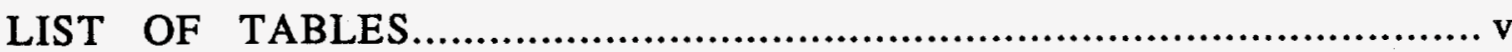

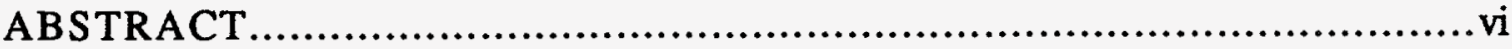

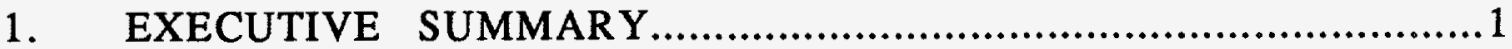

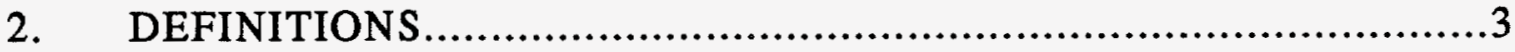

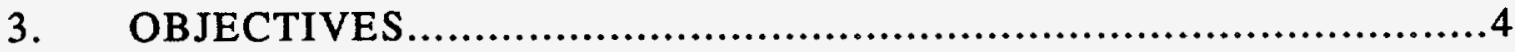

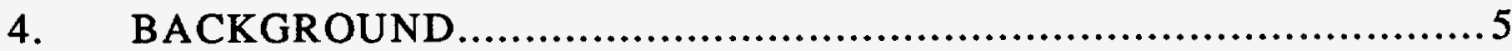

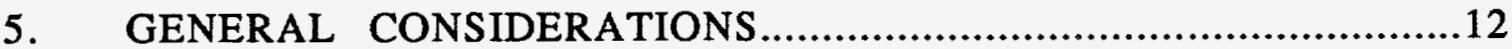

6. PROPOSED APPROACH AND METHODOLOGY .................................14

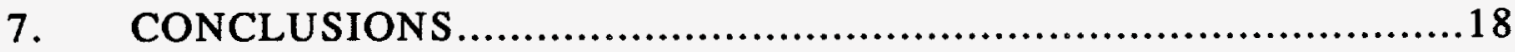

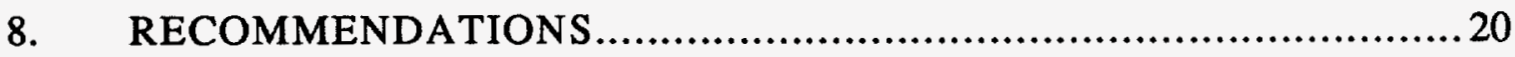

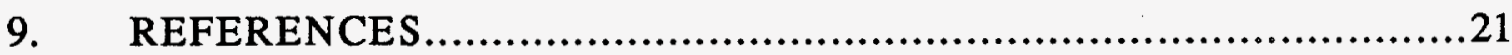

APPENDIX A. SUPPLEMENTAL GUIDANCE FOR DOE REACTOR FACILITY MAINTENANCE PLANS.............................................22

APPENDIX B. PREDICTIVE MAINTENANCE TECHNOLOGY...........................2 27

APPENDIX C. A PRA-GUIDED METHODOLOGY FOR DEVELOPING AN OPTIMIZED, ADAPTTVE NUCLEAR PLANT MAINTENANCE SCHEDULE BASED ON SAFETY, PREDICTABILITY, AND USER DEMAND 


\section{LIST OF FIGURES}

Figure 1. HFIR Availability for Various Time Periods....................................... 6

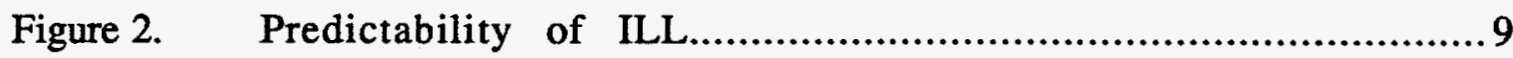

Figure 3. DOE Nuclear Facility Project Management Configuration Control...........15

Figure B1. Maintenance terminology (after Mercier, B.6)..................................29

Figure B2. A typical trend plot and terminology............................................. 31

Figure B3. The PM Program: Develop the actual maintenance plan and preventive maintenance program (after Mercier, B.67).......................................33

Figure B4. Steps in a Predictive Maintenance Program...................................... 35

Figure B5. Basic Steps and Analytical Tools Used for Establishing a General

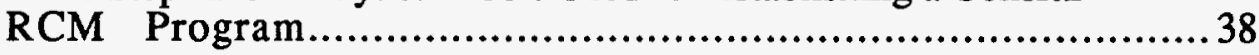

Figure B6. Data Acquisition System Showing Signal Conditioning Devices, Signal Multiplexer, and PC-based A/D Conversion..............................41

Figure C1. Flow chart of the methodology...............................................48

Figure C2. Data from component degradation instrumentation are extrapolated to predict time of component failure............................................. 50

Figure C3. Failure frequency and probability distribution when meanlife of components in plant proves to be shorter than expected..........................52

Figure C4. Failure frequency and probability distribution when meanlife of components in plant proves to be longer than expected..........................53

Figure C5. Using PRA to find a component failure probability limit $\mathrm{D}_{\mathrm{a}} \ldots \ldots \ldots \ldots \ldots \ldots . . . . .55$

Figure C6. The required safety/availability schedule for components 1,2 , and $3 \ldots . . .55$

Figure C7. Development of the adaptive schedule for maintenance of components 1,2 , and 3 and service of users $\mathrm{A}$ and $\mathrm{B}$ 


\section{LIST OF TABLES}

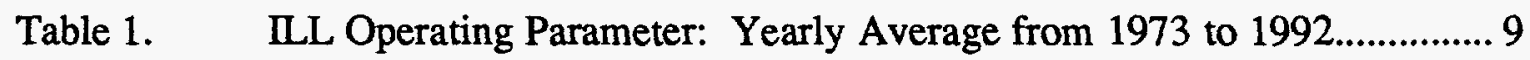

Table A1. Maintenance Factors to Increase Predictability.................................. 26

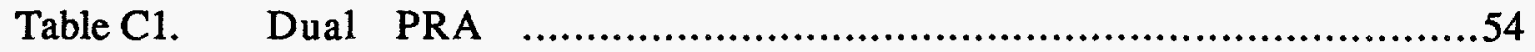




\begin{abstract}
A program is recommended for planning the maintenance of DOE nuclear facilities that will help safety and enhance availability throughout a facility's life cycle. While investigating the requirements for maintenance activities, a major difference was identified between the strategy suitable for a conventional power reactor and one for a research reactor facility: the latter should provide a high degree of predicted availability (referred to hereafter as "predictability") to its users, whereas the former should maximize total energy production. These differing operating goals necessitate different maintenance strategies. A strategy for scheduling research reactor facility operation and shutdown for maintenance must balance safety, reliability, and predicted availability. The approach developed here is based on three major elements: (1) a probabilistic risk analysis of the balance between assured reliability and predictability (presented in Appendix C), (2) an assessment of the safety and operational impact of maintenance activities applied to various components of the facility, and (3) a data base of historical and operational information on the performance and requirements for maintenance of various components. These factors are integrated into a set of guidelines for designing a new highly maintainable facility, for preparing flexible schedules for improved maintenance of existing facilities, and for anticipating the maintenance required to extend the life of an aging facility. Although tailored to research reactor facilities, the methodology has broader applicability and may therefore be used to improve the maintenance of power reactors, particularly in anticipation of peak load demands.
\end{abstract}




\section{EXECUTIVE SUMMARY}

A primary purpose for DOE nuclear reactor facilities is to provide neutron and gamma irradiation sources or environments for use by scientific programs. Therefore the operation of such facilities differs significantly from the operation of commercial nuclear power plants. This supplemental guidance identifies the special consideration needed to deliver predictability for a reactor that must accommodate many "one of a kind" experiments; for example, the Advanced Neutron Source (ANS) facility expects to have over a 1000 "small science" users annually and will have about 50 neutron beam stations.

The objective of this study is to develop a dynamic maintenance management program that will improve safety, provide predictability, ${ }^{1}$ and extend the life of DOE's nuclear research reactors. To assure that facility safety is not compromised, it heads the list of the various objectives. The emphasis among these areas is dominated by DOE's challenging requirements for predictable performance from its research reactors, such as the $90 \%$ predictability goal established for the ANS. Achieving predictable facility performance is recognized as the major challenge in optimal scheduling of maintenance activities. Life extension is incorporated in these objectives to assure that maintenance activities extend rather than compromise a facility's anticipated life.

Assurance of facility safety is to be achieved by the maintenance program, using guidelines presented in existing DOE orders, supplemented by improved plant condition monitoring, failure analysis prediction, and data management.

Achieving the goal of predictability will provide a high probability that a facility such as ANS will actually be available to customers at the time(s) previously scheduled, i.e., without schedular delays or disruption by unanticipated events. Existing program requirements, documents, and various maintenance concepts were found to be adequate to assure safety and life extension, but it was felt that additional attention should be given to defining methods for improving predictability. The ANS project was selected as the primary application for these innovative maintenance procedures, as it provides a unique opportunity to initiate the maintenance planning during the design phase of a reactor facility. The ANS project is designing the plant and, as stated above, has established a goal to deliver $90 \%$ predictability. Lessons learned and operating experience gained from ORNL's High Flux Isotope Reactor (HFIR), plus reports of France's Institute Laue-Langevin (ILL) reactor operating history, provide some indication of the feasibility of delivering this desired $90 \%$ predictability performance.

Three factors were identified as critical to maintenance approaches that will improve predictability: (1) flexibility in scheduling the plant's maintenance activities, (2) more and better monitoring of plant conditions, and (3) use of better probabilistic analytical tools for scheduling experiments and shutdown periods.

The scheduling methodology described here endeavors to (a) provide a flexible framework within which to apply advanced PRA-based maintenance techniques, (b) outline a generic approach applicable to research reactor facilities, and (c) go a step beyond maintenance, safety and conventional availability considerations in order to integrate user-demand into a

1 See Section 2, "Definitions," for the precise meaning of this term. 
dynamic, adaptive maintenance/user schedule that is continually adapted to changing conditions of the plant and the demands being placed on it.

The monitoring objective of the maintenance approach is to extract trending and diagnostics information from the plant component/system monitoring data. Designing for effective maintenance must include the following aspects: (a) a systematic identification of critical components that require continuous or periodic monitoring, (b) a systematic evaluation of instrument placement strategy for both predictive maintenance (PdM) and facility monitoring, (c) establishment of a database that would contain maintenance history, records of chronic problems with plant components and subsystems, equipment replacement records, manufacturer and vendor data, and other information that is relevant to plant operation and availability.

Probabilistic risk analysis tools are to be used to select particular time periods for scheduling preventive or predictive maintenance activities so as to assure a high probability of facility safety, a low probability of unscheduled outage, a minimum of interference with user schedules, and optimal replacement of fuel and disposable components. These analyses will lead to a flexible schedule of accelerated or deferred maintenance activities necessary to meet predictability goals. This approach for using PRA in maintenance scheduling is developed in Appendix C.

The physical and neutronic demands being placed on the ANS exceed those of almost all existing reactors and may later require revision of the intended maintenance activities to operate within these requirements. Clearly, the designers and operators of ANS may benefit from "smart," dynamic surveillance techniques and maintenance procedures that inherently evolve with the plant, maintain required safety margins, and assure expected plant availability. In addition to safety and the conventional concept of availability, this facility has the additional operating goal of providing services to users on a predetermined timetable for such things as small-angle scattering experiments, isotope generation, etc.

The designers and operators of ANS therefore have need of a dynamic maintenance program that is adaptive and flexible, one that will optimize the safety, availability, cost, and life cycle capabilities of this DOE facility. The guidance provided in this report, while challenging in its employment, could help provide the level of performance required of the ANS. The results of this study lead to the following recommendations, which are expanded in the Recommendations section of the report:

1. Employ a dynamic, PRA-based, risk analysis approach to the maintenance and user scheduling process.

2. Assess the plant components, systems, and structures for their impacts upon safety and reliability. Identify new or modified components. Identify particular maintenance requirements for these components. Maintain this list as plant improvements are made.

3. Provide an assessment of available physical and personnel resources, and a cost/benefit analysis for maintenance planning. Update these analyses frequently throughout the facility's life cycle.

4. Insist on component modularity and include performance monitoring equipment in the original plant design. 
5. Use computer simulation (a) to guide a more detailed pilot study of implementation of a computerized PRA for an existing or proposed facility, and (b) to generate a template for the operating history, component degradation and failure records, and user demand for the facility to which the PRA applies.

Although this work specifically addresses maintenance of research reactor facilities such as the ANS, much of what is developed here may also be useful in improving maintenance at nuclear power plants which need to schedule operation to meet peak load demands or coordinate maintenance shutdowns among several units.

\section{DEFINITIONS}

\section{Availability}

Global Availability (GA): defined as the number of full power days (FPD) of operation achieved during a one-year period, divided by the number of days in a year:

$$
\mathrm{GA}=\mathrm{FPD} / 365 \text {. }
$$

Planned Operating Days (PODs): defined as the particular days in a given time period when the facility is planned to operate. The maximum number of PODs cannot exceed the number of days in a year (365) less the number of days required for refueling (RFD), planned maintenance days (PMD), and annualized planned replacement days (PRD), that is,

$$
\mathrm{POD} \leq 365-\mathrm{RFD}-\mathrm{PMD}-\mathrm{PRD} .
$$

\section{Predictability}

Predictability (P): defined as the number of scheduled FPD actually realized during a year of facility operation divided by the total number of FPD scheduled in advance for that year:

$$
\mathbf{P}=\text { Scheduled FPD Achieved/Scheduled FPD. }
$$

As an example, using the proposed operation/maintenance schedule for the ANS: An annualized 39 days each year are planned for replacement of major components and 15 days are planned for scheduled maintenance, leaving 311 days for expected operation:

$$
365-39-15=311 \text { days. }
$$

Those 311 days allow 14 complete operational cycles with each cycle consisting of seventeen (17) full power days operating followed by four (4) days of refueling, or a total of 294 days. The remaining 17 days (311-294) could be scheduled as 17 operating days without refueling, or as 13 days of operating plus 4 days of refueling (a short cycle), or as additional maintenance or replacement days. Hence the anticipated number of planned operating days (POD) is 238:

$$
17 \text { days } \times 14 \text { cycles }=238 \text { POD (anticipated). }
$$


The ANS project requires that a minimum of $220 \mathrm{POD}$ be scheduled each year, with a goal of 270 days, which would require giving up some maintenance or replacement days. In effect, this requirement avoids the situation where only a few days are scheduled and met.

If each of the 238 possible POD are scheduled for operation on specific days during the coming year, and the facility actually produces neutrons on those particular days, the predictability of the facility would be $100 \%$. For the ANS, it is required that the predictability be $>85 \%$ of the required 220 POD.

\section{OBJECTIVES}

The objectives of this study are to identify and describe specific maintenance actions that

1. help assure the safety of Department of Energy (DOE) nuclear reactor facilities,

2. improve their predictability, with particular attention to scheduled user demand, and

3. extend their life.

These objectives are to be achieved by employing a plan that predicts and schedules maintenance activities in a manner that enhances facility safety, reduces risk of unanticipated outage to an acceptable level, provides a minimum of $85 \%$ facility predictability to the scheduled users at the scheduled time, and supports operation of the facility throughout and beyond its entire design life.

In these discussions "predictability" specifies those operating days that are spent on producing neutrons (or conducting experiments) exactly when they were scheduled to be produced (or conducted). Therefore, a premium is placed on strict adherence to a predetermined schedule as well as to provide as many operating days as possible.

The plant's predictability was singled out for special study due to DOE's high expectations in this area, as indicated by the $85 \%$ predictability requirement called for in the ANS design specifications. In light of ANS's twenty-one day power cycle, the predictability history of ORNL's HFIR and that of Institute Laue-Langevin (ILL) reactor, the $90 \%$ goal presents a serious challenge.

\section{BACKGROUND}

\section{Maintenance Plans}

Each DOE research reactor facility must have maintenance plans that satisfy the dictates of its contractual obligations. These plans are developed in accordance with the program's maintenance strategy, and in compliance with regulatory guides/directives to assure that the operation of the plant is safe and economical. Traditionally, generation of maintenance plans for nuclear facilities has been performed at or near the plant startup, usually by adopting maintenance plans used for previous facilities and by relying on scheduled maintenance. The maintenance plan that complies with requirements and is suited to the plant's condition early in life often creates problems that are caused by misapplied 
maintenance and soon becomes obsolete due to changing plant conditions over time. The maintenance plan proposed in this report seeks to avoid unnecessary maintenance and to adopt a dynamic maintenance plan. The results of this task are not intended to change or replace any contractual or compliance requirements for these maintenance plans, but rather, they are expected to provide information that will supplement the project's guidance for development of its maintenance plans. It is intended that this additional guidance will help DOE and the facility's management to plan and implement changes that will further assure safety and improve the reactor's predictability.

\section{Other Reactor Experience}

\section{Summary of HFIR Availability, Predictability, and Maintenance}

The HFIR is used for production of heavy isotopes, materials irradiation, and neutron scattering research. It began power operation in 1966 and has an operating strategy of maximum availability. Figure 1 shows HFIR availability for various operating periods. These values were calculated from HFIR records for each reactor core burned in the facility.

From October 1966 to November 1986 (1967-1987), HFIR achieved an impressive availability of $85 \%$, shown as the left-most bar in Figure 1. The maximum possible availability for HFIR is estimated to be $92 \%$, based on an average core life of 21.9 days and minimum refueling time of about two days. Thus, during its first 20 years of operation, HFIR availability was maintained within $7 \%$ of its maximum possible value, while operating at $100 \mathrm{MW}$ full power.

From November 1986 to May 1990, the facility was shut down because of safety concerns associated with radiation-induced embrittlement of the pressure vessel. 2 Power operation was resumed in May 1990 at $85 \mathrm{MW}$, rather than the original value of $100 \mathrm{MW}$, and the average availability since that time has been about $57 \%$, shown as the second bar in Figure 1 (1990-1994).

HFIR availability during power operation (October 1966 to November 1986 and May 1990 to April 1994) averaged $80 \%$, as shown in the middle bar in Figure 1, designated as the "Power Years" (eliminating a long shutdown during 1986-1990). Its availability since the start of power operation (October 1966 to April 1994) has been 70\%, as shown in the fourth bar of Figure 1. The average availability since initial criticality in January 1966 (1966-1994) is 69\%, including the safety shutdown period.

2 G. F. Flanagan, et al., Risk and Safety Analysis in Support of the Operation at the High Flux Isotope Reactor at Oak Ridge, International Atomic Energy Agency Symposium on Research Reactor Safety, Operations, and Modifications, 23-27 October 1989, IAEA-SM-310. 


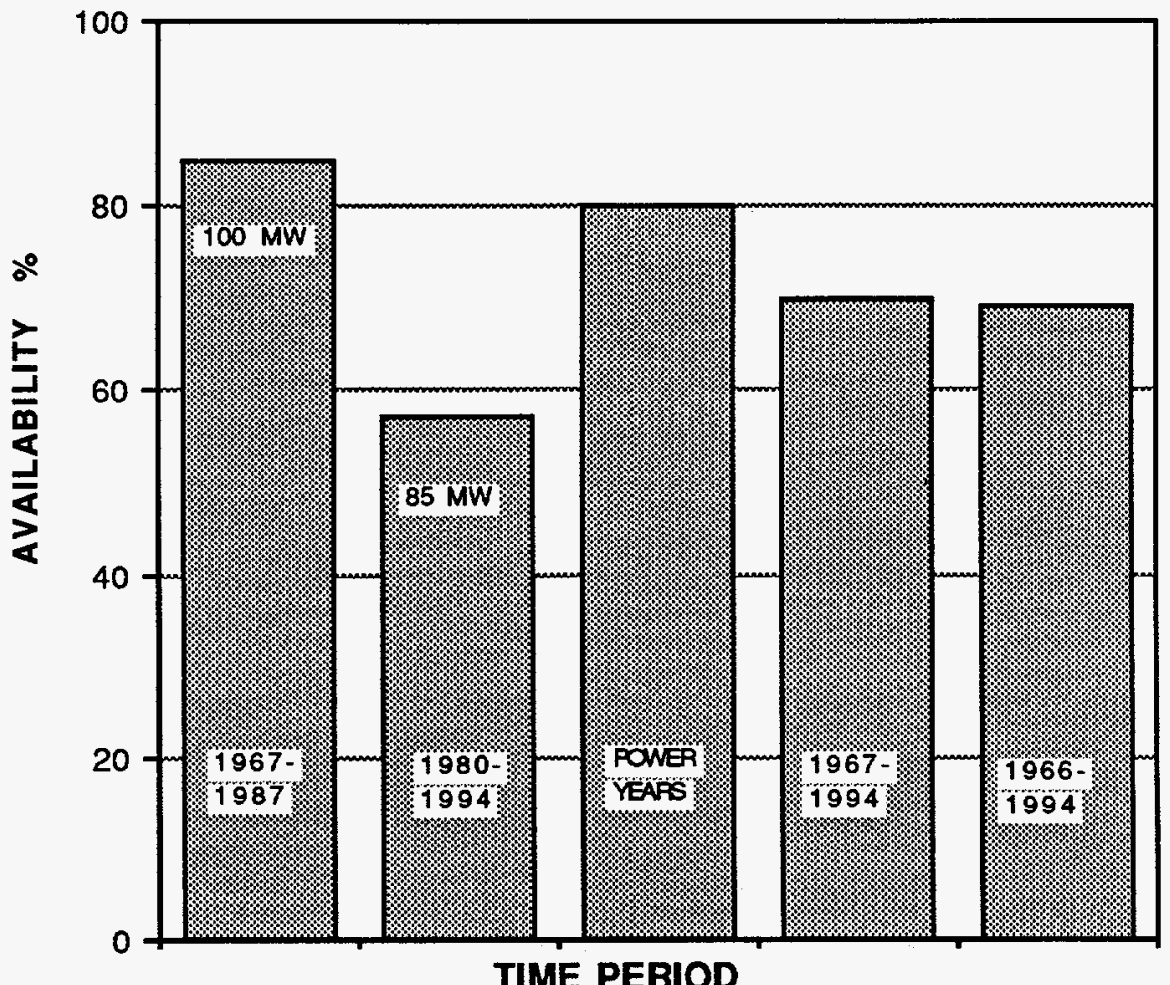

TIME PERIOD

Figure 1. HFIR Availability for Various Time Periods.

The predictive availability, or predictability, of the HFIR facility was recently studied by the HFIR staff with the aid of a subcontractor ${ }^{3}$. Their paper defined predictability as:

Predictability $=$ Time at power when scheduled $/$ Total time scheduled to be at power

Thus, predictability measures success in operating the reactor exactly as scheduled in advance on a yearly basis. Note that no credit is given for power operation on days for which power operation had not been scheduled.

One result of this study is that availability and predictability are numerically about the same for HFIR-type operation. Several curves in the paper illustrate this conclusion. A second, rather obvious result is that the more often the schedule is updated, the higher the predictability becomes with respect to availability. For HFIR, achieving a planned scheduled is secondary to achieving maximum availability, since the primary function of

3 Larry Merryman, Eric Ballon, and Bob Christie, Predictability vs. Availability at the High Flux Isotope Reactor, International Conference Devoted to the Advancement of System-Based Methods for the Design and Operation of Technological Systems and Processes, March 20-24, 1994, San Diego, California. 
the facility is isotope production. Thus, consistent with its primary mission, predictability has not been emphasized by HFIR.

The relationship between predictability and availability for HFIR is consistent with theoretical considerations. Let $P(a)$ be the probability that event "a" will occur and $\mathrm{P}(\mathrm{a} / \mathrm{s})$ be the probability that event "a" will occur given that event "s" has occurred. Then predictability, in terms of probabilities, can be expressed as:

$$
\mathrm{P}=\mathrm{P}(\mathrm{a} / \mathrm{s})
$$

where " $\mathrm{s}$ " is the event that the reactor is scheduled to be on, and "a" is the event that the reactor is actually on. Or, $P(a / s)$ is the probability that the reactor is operating given that it is scheduled to be operating.

A useful relationship from probability theory exists between this conditional probability and the probability that both "a" and "s" will occur. Thus, if $P(a, s)$ is the probability that event "a" and "s" will occur, then $P(a, s)=P(s) * P(a / s)$. Using this relationship, we can express the predictability as

$$
\mathrm{P}=\mathrm{P}(\mathrm{a} / \mathrm{s})=\mathrm{P}(\mathrm{a}, \mathrm{s}) / \mathrm{P}(\mathrm{s}) .
$$

Now, if the planned schedule and the actual schedule are independent events (an extreme case); then, again from probability theory, $P(a, s)=P(a) * P(s)$. Substituting this expression into equation (2) yields:

$$
\mathrm{P}=\mathrm{P}(\mathrm{a})=\mathrm{A}=\text { global availability. }
$$

The above is a reasonable approximation for cases, such as HFIR, where the predicted schedule is only an estimate or guide, and the operating strategy is to have the greatest energy production (commercial plants) or fluence (isotope production) at any time. The above expression can be considered an average lower bound on predictability for situations where availability is stressed and predictability is not.

A Reliability Centered Maintenance (RCM) program was initiated at HFIR in August 1992.4 The purpose of this program is to improve overall plant performance by monitoring selected, critical components to determine their impacts on reactor availability and safety. The first step in the process was to identify the critical components. This was done through review of reactor performance using selection criteria. Critical components are those that had: (1) a substantial impact on time spent at power, (2) a substantial impact on the HFIR maintenance workload during a recent four-year period; (3) a safety significance; (4) delayed refueling or caused a longer outage than planned during this same four-year period; or, (5) caused a significant operational problem. About 50 normally running components and about 30 standby components were selected using the above criteria. These critical components are tabulated in the report. Normally running components in this list included primary, secondary, and cleanup pumps; primary heat exchangers; fans

4 Draft report from Bob Christie, Reliability Consultant, Reliability and Performance Associates (RAPA), Knoxville, Tennessee, Reliability-Centered Maintenance Equipment Data Base for the High Flux Isotope Reactor, September 21, 1993, Report Prepared for HFIR by Reliability and Performance Associates, Knoxville, Tennessee. 
used in building exhaust and off-gas systems; selected valves; and selected instrumentation. Prominent among the standby components were emergency diesel generators, auxiliary emergency power generators, batteries, and valves. Information collected for these components are being used to generate reliability/availability models to aid in facility operation.

\section{Summary of ILL Availability, Predictability, and Maintenance}

The Institute Laue-Langevin (ILL) research facility began operation in 19735. The primary focus of ILL is to provide neutron beams for scattering experiments. The operating strategy of ILL was established in 1975 after two years of operation. This strategy stresses high predictability and the capability to extend an operating cycle to recover lost powerdays. The core life is 44 days and 12 days are allowed for refueling, even though the minimum refueling time is about 4 days. 6 About 6 cycles are scheduled each year, and a one-month facility shutdown for maintenance is often scheduled around October.

The following table lists several ILL parameters associated with operation for about 20 years. The material in this table was generated using tabulations and summary-ofoperations information contained in ILL's annual reports. Most notable is the predictability value of $89 \%$ achieved for this extended time period. For three of these years $(1980,1986$, and 1987) a predictability of $100 \%$ was achieved!

Operation is planned near the beginning of the calendar year and a careful accounting of operation achieved vs. operation scheduled is tabulated at the end of the year. Scheduled operating days each year have averaged 237, which is close to the stated optimum of 264 $(6 \times 44)$. As summarized below, some of these unscheduled days were used for facility upgrades.

ILL operates so that predictability is optimized. The average scheduled global availability has been about $65 \%$ even though, by our calculations, the maximum availability is significantly higher, in the range of $85 \%$ to $90 \%$. This "cushion" in the planned schedule probably contributes to high predictability. From 1973, when power operation began, to 1992 an average availability of about $60 \%$ was achieved. Over this same time period, unanticipated unavailability was only $10 \%$.

[In response to a reviewer's (JAM) comments, it is apparent that there is a possible tradeoff between availability and predictability and that an analysis might be developed to optimize this trade-off. This seems to be an idea worth pursuing during the requirements definition phase of the project, but once the minimum number of scheduled planned operating days (220 POD for ANS) and the minimum acceptable predictability (85\% for ANS) has been established, meeting those two goals becomes an obligation of the facility's operators, and allows enough lattitude to meet both requirements. The ILL experience indicates that the ANS requirements should be achievable.]

5 Annual Reports have been published by ILL each year since operation began. These are published under the title, Annual Report 19xx, (the year of the report is included in the title), Institut Max Von Laue-Paul Langevin, Grenoble, France, ILL.RA.19xx.

6 Personal communication, John Hayter, Oak Ridge National Laboratory. 
A plot of ILL availability and predictability vs. years of operation is shown in Figure 2.

Also shown is a model estimate of the predictability of ILL based on its global availability.

\section{Table 1.}

\section{ILL OPERATING PARAMETER: YEARLY AVERAGE FROM 1973 TO 1992}

Planned Operating Days

237.11

Actual Operating Days

218.84

Global Availability Planned

$65 \%$

Global Availability Achieved

$60 \%$

Days not Operating when Planned

25.44

Predictability

$89 \%$

Planned Major Maintenance Days

57.66

Actual Major Maintenance Days

50.13

Number of Unscheduled Shutdowns

10.21

Shutdowns with Xenon Poisoning Extension

2.53

Days Lost to Xenon Poisoning

Days at Partial Power

Unscheduled Unavailability (25/237)

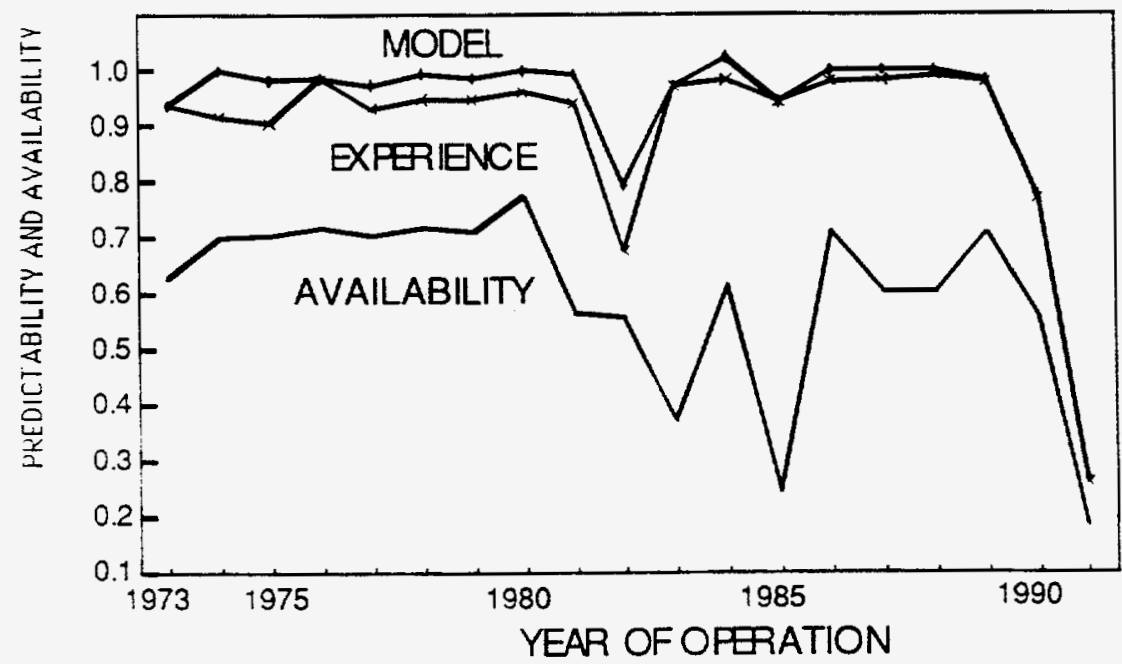

Figure 2. Predictability of ILL.

The model estimate was based on the operating strategy for the facility. If we assume that operation occurs only when planned, then:

$$
\mathrm{A} \leq \mathrm{S}
$$

where $S$ = the planned global availability, and $A=$ the actual global availability From equation (1) above

$$
P=P(a / s) .
$$


A more useful expression for predictability, in this case, is

$$
\mathrm{P}=1-\mathrm{P}(\mathrm{na} / \mathrm{s})
$$

where, by definition, $P(\mathrm{na} / \mathrm{s})$ is the probability that the reactor is not operating when scheduled to be operating. Other terms for $\mathrm{P}(\mathrm{na} / \mathrm{s})$ are unanticipated unavailability or spurious failure probability. The ILL operating strategy is to make this term as small as possible, thereby making predictability as large as possible.

An approximation for $\mathrm{P}(\mathrm{na} / \mathrm{s})$ is possible. If one stresses matching the actual schedule to the planned schedule and operates such that actual availability is always less than planned availability, then an estimate for $P(\mathrm{na} / \mathrm{s})$ is:

$$
\mathrm{P}(\mathrm{na} / \mathrm{s})=(\mathrm{S}-\mathrm{A}) / \mathrm{S} \text { for } \mathrm{A} \leq \mathrm{S} ; \mathrm{S}>0 .
$$

Thus

or,

$$
P=1-(\mathrm{S}-\mathrm{A}) / \mathrm{S}
$$

$$
\mathrm{P}=\mathrm{A} / \mathrm{S} \text { for } \mathrm{A} \leq \mathrm{S}>0 .
$$

This simple expression does not include the intuitive rules that: (1) to keep predictability high, one should have a high probability of always starting a cycle on time; and, (2) if the schedule has slack for recovery from spurious failures, then predictability can be high even if availability is relatively low.

By combining the previous derivations with the above estimate, a range for predictability is obtained which covers a wide range of operating strategies:

$$
A \ll P «(A / S)
$$

Operation and maintenance experience at the ILL facility is summarized below from the perspective of identifying major causes for loss of predictability and availability.

- $\quad$ Several failures in the main coolant pumps occurred, mainly during the first few years of operation. The cause was overheating of the pump bearings. This required operation at reduced power due to the reduced primary-system cooling capacity. The problem was solved by more frequent maintenance and replacement of the pump systems.

- An average of 10 unscheduled scrams per year have occurred; however, the number each year has decreased with operating experience. A large fraction of these scrams were due to relatively unreliable off-site power, particularly during thunderstorms. Sensitivity to loss of off-site power was alleviated somewhat in 1981 when the duration of a loss which could be accommodated without reactor scram was increased from 0.5 seconds to 1.5 seconds.

During the first few years of power operation, a significant fraction of the scrams were due to unnecessary safety-circuit actions during startup; these were subsequently reduced. In about half of the unscheduled scrams, power level could be restored quickly before the buildup of xenon prevented recriticality. For the 
remainder, the reactor was down for about 4 days until xenon decay allowed restart. If the unscheduled scram occurred after the 30th day of power operation, the cycle was terminated, since there was not enough reactivity to continue the cycle. The reactor could subsequently be restarted without significant loss in predictability.

- In 1983, five beam tube liners were replaced during an extended shutdown of about 7 months. Leakage of coolant through the beam tube liners had been detected prior to this time and had resulted in noticeable loss of availability.

- Replacement of reactor system components due to radiation damage occurred in 1984 after 13 years of ILL operation. This replacement occurred over about a ninemonth period. It is not clear if all this time was required for the replacement, since other repair and maintenance activities were also done during this shutdown.

- In 1987 and 1988, a significant upgrade in the cold source facility was accomplished. A vertical cold source was added and the horizontal cold source was significantly improved. These operations required several months to accomplish.

- In 1988, a limit in the supply of new fuel elements caused about 2 months loss in operation. This problem was corrected the following year.

- In 1990, it was discovered that the reactor had inadvertently been operated at about $10 \%$ above rated power since the start of operation. The safety authorities required shutdown for about 3 months while this situation was investigated and resolved to their satisfaction.

- In 1991, cracks were discovered in reactor components during a routine inspection. Due to the importance to safety of these components and the unexpected nature of the cracks, the facility was shut down. Facility operation is anticipated to resume soon.

\section{Standards}

Four standards have been adopted within the past year that provide "good practices" for maintenance activities in DOE nuclear facilities and for meeting the requirements of DOE Order 4330.4A, "Maintenance Management Program," Chapter II, Elements 6,1,4, and 7 respectively. They are:

DOE-STD-1050-93, "Guideline to Good Practices for Planning, Scheduling, and Coordination of Maintenance at DOE Nuclear Facilities," (March 1993)

DOE-STD-1051-93, "Guideline to Good Practices for Maintenance Organization and Administration at DOE Nuclear Facilities," (March 1993)

DOE-STD-1052-93, "Guideline to Good Practices for Types of Maintenance Activities at DOE Nuclear Facilities," (March 1993)

DOE-STD-1053-93, "Guideline to Good Practices for Control of Maintenance Activities at DOE Nuclear Facilities," (March 1993) 
These excellent guidelines provide details on the conduct of maintenance operations and identify planned, periodic, preventive, and predictive maintenance approaches, but apparently do not address the impact of predictability on maintenance planning for a nuclear reactor irradiation facility such as the ANS or the HFIR, nor are probabilistic methods identified that could be used to prioritize maintenance decisions. They also do not treat the features of plant design and component modularization that could expedite maintenance operations. DOE-STD-1052 does provide good directions for implementing a preventive maintenance program (\$ 3.4.3) and for a predictive maintenance program (ף 3.4.4). The present work (ORNL/TM-12701) provides some useful additions to the existing DOE Guidelines.

\section{GENERAL CONSIDERATIONS}

This study is focused on the maintenance requirements for the ANS, since it is the obvious opportunity to institute a maintenance program during the design phase of a nuclear facility. When the inevitable problems develop during the start-up and initial operation of ANS, changes will be made to accommodate and/or solve the problems. The solutions will take many forms but will never be permitted to compromise the safety of the public or operating personnel. Therefore, it may be difficult to find approaches that do not significantly impact cost, schedules, and plant availability. Funding constraints may leave facility management with the necessity of absorbing the changes in schedule and plant availability, which could challenge the program's ability to meet its $90 \%$ predictability goal.

Dynamic Maintenance: A modified maintenance plan should anticipate changes in maintenance requirements that result from: (a) failures during break-in of new components or designs, (b) changes in mission over the life of the facility; (c) obsolescence and unavailability of replacement components; (d) changes in codes and regulations; (e) operational experience; (f) fluence-induced changes in material properties; (g) mechanical wear out; and (h) process cycling, and (i) aging. These factors are all part of the dynamic time-related dimensions of the life cycle maintenance and operation of the facility.

- In the near-term (i.e., at the beginning of plant operation) the dynamic maintenance strategy should be predictive and preventive rather than simply schedular. It should utilize in-service inspection and diagnostic functions to indicate new requirements for maintenance that will help to avoid unnecessary shutdowns.

- In the mid-term, the strategy should include modification of the maintenance plan to reflect actual and similar plant experience, and be adaptable to new requirements dictated by changes in the facility mission or operational modes.

- In the long-term (i.e., as the plant approaches the end of its design life) the maintenance strategy should accelerate the frequency of monitoring actions in anticipation of component, structures, materials, and system end-of-life conditions.

[Additional considerations posed by a reviewer (JAM): The facility "design life" is based on the expected life of major components, whose replacement is impossible or would be too costly. Thus more frequent and closer component-condition monitoring is clearly justified towards the end of the component design life which corresponds with the end of the facility life. This principle should be applied to the monitoring of all components in the 
facility, provided that the closer monitoring is cost effective, i.e., it results in a net reduction of operating and maintenance $(\mathrm{O} / \mathrm{M})$ costs.]

Design Provisions: To improve its effectiveness in anticipating the mid- and long-term maintenance requirements, the maintenance strategy should be developed while the plant is being designed. This preplanning should help assure that provisions for changes are anticipated and included in the construction of the plant. The design of the facility should provide operational flexibility, space to accommodate changes, control and data capacity, and other features that will permit transitions to other plant missions. Components and systems should be designed to circumvent obsolescence by specifying generic properties that will accommodate new technologies or new materials.

[ Additional reviewer's (JAM) comments: It is unlikely that the plant designers will provide gratis the provisions that anticipate changes in the operational requirements. These features should then be made a part of the plant requirements imposed on the designers. Justification for adding these requirements must be based on a favorable cost-benefit analysis that minimizes initial plant construction costs and long-term $\mathrm{O} / \mathrm{M}$ costs.]

Modularization: A strategy for maintaining adequate spare parts inventory should be coupled with a plan for modularization of plant components so that they can be maintained off line, and with provisions for upgrading and improving the plant's safety and performance. These may appear to be conflicting objectives; however, they can be more easily reconciled in the initial design of the plant rather than later, after major investment of time and resources have been expended.

[Reviewer's (JAM) comments: Provisions of modularization in the initial design may be justified if modularization can be shown to be cost effective in reducing $\mathrm{O} / \mathrm{M}$ costs, reducing reactor down time, providing for off-line repair, facilitating upgrades and modernization, and reducing inventories of spares.]

Data Base: An effective maintenance operation must be supported with adequate information and an experience data base that is user friendly for the facility operators and its engineering staff. This data base should include: (a) plant design requirements; (b) rationale for selecting certain design features; (c) safety analyses of the plant; (d) specific details of the as-built construction of the plant, its operation, and its maintenance records; (e) manufacturer's tests and analyses of the predicted performance and aging of plant components; ( $f$ ) information on component and system actual behavior from other installations; (g) data collected from on-line monitoring, diagnostics, and in-service inspection of plant systems; and (h) failure and trending analysis of plant systems. This data base should then be used to predict and plan effective maintenance operations that support the goals of safety and predictability for the facility.

Training: Maintenance personnel must be trained and supported by information generated in the initial design process, and must follow procedures that will be modified as the maintenance needs of the plant change. This dynamic maintenance function can be managed by providing maintenance guides in electronic form with an updating system that uses information in the maintenance data base. An interactive association between the engineer and the technician should be encouraged and supported. Portable electronic guides and record-keeping capabilities can be provided to the technicians. Results can then be recovered and interpreted by the maintenance engineer. 
Safety: The safety goal of a DOE nuclear facility includes protection of the public, the facility personnel, and the plant investment throughout construction, operation, and shutdown of the facility. Also, during unanticipated changes in mission and operational requirements that occur as the plant ages, a well considered maintenance program is an essential ingredient in the plant operator's program to assure safety.

\section{PROPOSED APPROACH AND METHODOLOGY}

A primary purpose for DOE nuclear reactor facilities is to provide neutron and gamma irradiation sources or environments for use by scientific programs. Therefore their operations differ significantly from the operations of commercial nuclear power plants. This supplemental guidance recognizes these differences and the continuing need to provide safety for the public and the operators. It also identifies the special consideration needed to deliver predictability for a reactor that must accommodate many "one of a kind" experiments (for example, ANS expects to have over a 1000 "small science" users annually and will have about 50 neutron beam stations).

The approach proposed by this study recommends using the existing maintenance plans, scheduling systems, probability risk analyses, and failure mode analyses as inputs for three evaluations. These evaluations are to focus on the development of (1) features to be incorporated in the plant design that will enhance maintenance operations and improve scheduling quality; (2) improvements in the maintenance plans and procedures; and (3) modifications of the scheduling system to increase the use of probability risk analyses and failure mode analyses. It is expected that these evaluations will lead to improved maintenance plans and the modification of maintenance schedules in ways that will improve both safety and predictability. This process is depicted in the diagram shown in Figure 3.

Effort should be devoted to the identification of design features that will improve the flexibility of the maintenance operations and assure space for the use of new monitoring instrumentation. Additional monitoring instrumentation is recommended to assure that the PRA and FMA are based on complete and accurate plant performance information. The plant's maintenance plans and procedures should be examined periodically to assure that they incorporate the latest maintenance concepts and techniques. These approaches are summarized in section 6.1 and described in more detail in Appendix A. A survey of various applicable maintenance approaches was conducted, is summarized in section 6.2 , and in Appendix B. Preliminary work was performed to assess the merits of developing a new approach for scheduling maintenance operations based on more extensive use of PRA's and FMA's. An outline of this new scheduling system that takes full advantage of the maintenance flexibility provided in the design, the use of advanced maintenance concepts, and currently updated PRA's and FMA's is discussed in section 6.3 and in Appendix C. 


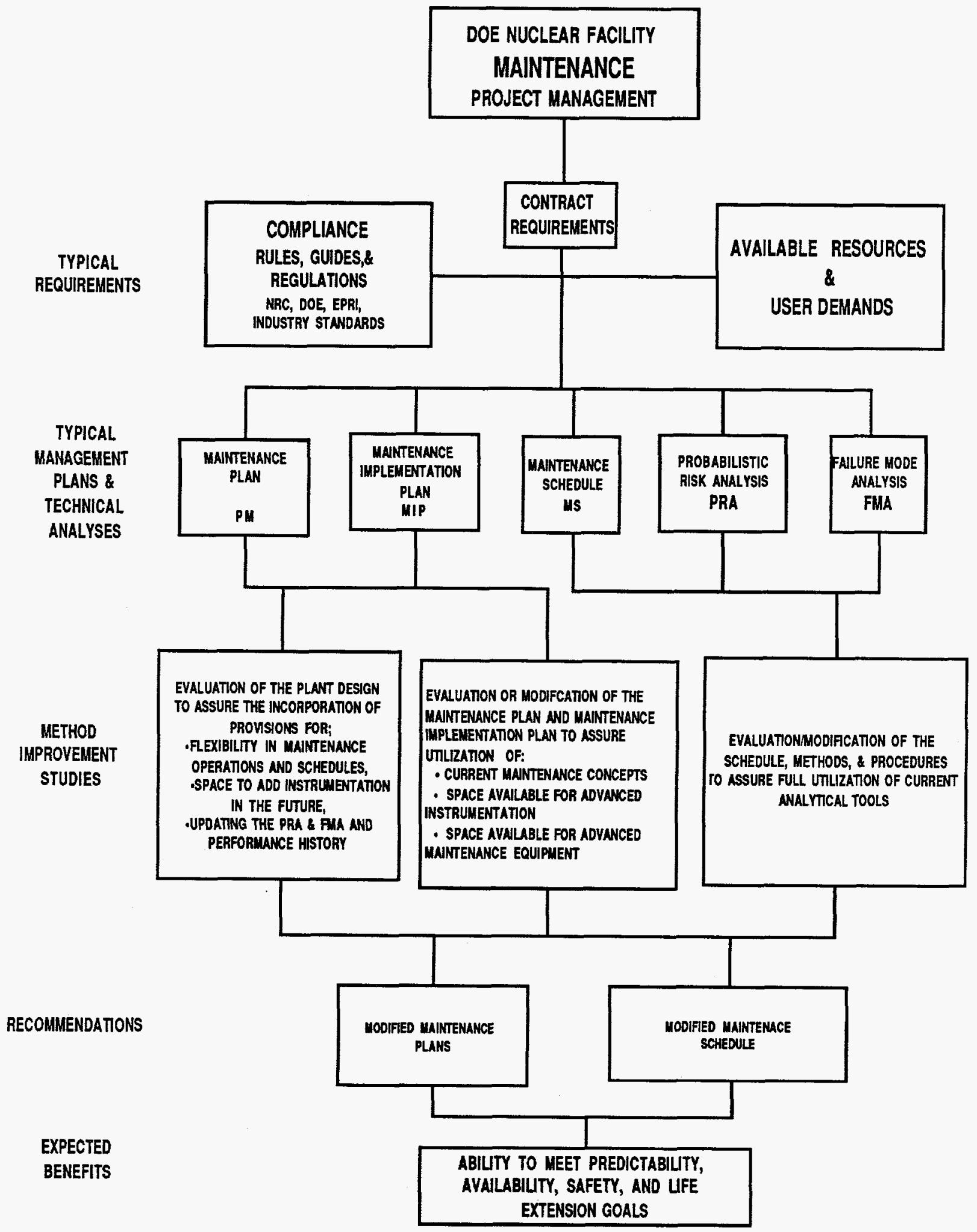

Figure 3. DOE Nuclear Facility Project Management Configuration Control. 


\subsection{DESIGN FEATURES TO IMPROVE MAINTAINABILITY}

Design reviews should be conducted with the express purpose of identifying cost-effective ways to improve the reactor's maintainability. Design reviews conducted as a normal part of the initial design process should have segments that focus on the incorporation of features specifically aimed at improving the plant's predictability. The following features were identified as generic and important for ease of maintenance:

- Maximum use of tiered modular design. Such an approach will enhance the maintenance staff's ability to replace small subassemblies and avoid in-place repair that have significant impacts on the schedule. The subassemblies can be repaired in the maintenance shop without impacting the operating schedule.

- Consideration of the cost effectiveness of installed spares and hot switching strategies for maintenance of some systems.

- The incorporation of ample space in the plant design to provide access for fast replacement of subassemblies.

- The incorporation of ample space in the plant design to add new instrumentation found to be important during the first few years of operation. Space must also be available if the plant is to be in a position to incorporate advanced instruments and systems as they become available.

- The equipment and building arrangement should likewise anticipate the need of new maintenance equipment and, in particular, telerobotic systems to meet ALARA and predictability goals. It is important to provide space for mobility; wall and roof attachments; services (e.g., electric and pneumatic power, computer/data networks, etc.), and to allow for expansion of data aquisition and processing networks and systems.

Periodic reviews should be conducted to assess the needs of the maintenance staff and the merits of incorporating additional design features that will improve their operations. After the first few years of operation, there should be a conscious effort to define how the space in and around the components can be used to improve the predictability.

\subsection{UTILIZATION OF NEW MAINTENANCE CONCEPTS:}

A survey of the current literature on the concepts available for use by maintenance organizations indicates the following issues should be considered in the design of a new facility for effective maintenance during its life:

- A systematic identification of critical components that require continuous monitoring. Their availability is essential to the predictability of the facility. Reliability Centered Maintenance (RCM) or an equivalent approach may be applied to achieve this goal.

- A systematic evaluation of instrument placement strategy for both predictability maintenance and plant monitoring. The choice of smart sensors and intelligent machinery should be reviewed. 
- Establishment of a database that would contain maintenance history, dynamic data, records of sustained problems in certain plant components and subsystems, equipment replacement records, manufacturer and vendor data, and other information that is relevant to plant operation.

- A computer-based diagnostic and interpretive system that will use the information in the database to provide guidance for operation and maintenance of the facility.

Such a program is evolutionary in nature and must be allowed to change as increased plant operating experience is accumulated. Advanced and effective information processing techniques are now available for establishing an economical maintenance program for rotating machinery, instrument channels, electrical components and systems, lubrication oil systems, actuator systems, heat exchangers, and many others. The use of nondestructive examination for in-service inspection is becoming a standard practice for certain nuclear plant components.

The overall purpose of the work described here is to define and elaborate on a maintenance strategy that will maximize the predictability of DOE research reactors without compromising their safety.

The anticipated strategy will call for a flexible maintenance program that includes the essential maintenance tasks while incorporating features of a condition-based maintenance philosophy wherever possible. To accomplish this end the instrumentation incorporated in the facility must be extensive and capable of delivering ample real-time data during all operating periods.

It is anticipated that diagnostic information will be gathered during each power cycle from the permanent in-reactor instrumentation and from the test assembly instrumentation. This information will guide the updating of maintenance plans for implementation during every refueling period and/or planned retrofit period.

For a new facility the establishment of a maintenance schedule is necessarily based upon equipment manufacturers' recommendations and/or performance records from similar components in other facilities. After the plant goes into service, this initial schedule may need modification if actual component life differs significantly from expected. Facility owners and managers may benefit from smart, dynamic surveillance techniques and maintenance procedures that inherently evolve with the plant and maintain required safety margins and assure expected plant availability.

Operators of commercial plants are giving increasing attention to enhanced maintenance approaches such as the use of probabilistic risk analysis (PRA) to quantify safety and availability risks as a guide to maintenance. Research reactor facilities commonly have an additional operating goal of providing services to users on a predetermined timetable for small-angle scattering experiments, isotope generation, etc. The methodology described here endeavors to (a) provide a flexible framework within which to apply PRA-based maintenance techniques, (b) outline a generic approach applicable to research reactor facilities, and (c) go a step beyond maintenance, safety and conventional availability considerations in order to integrate user demand into a dynamic, adaptive maintenance/user schedule that is continuously tuned to changing conditions of the plant and the demands placed on it. 
[It was pointed out by one of the peer reviewers (RLC) of this report that the addition of extensive condition monitoring instrumentation could increase the number of manhours required by the maintenance department to calibrate and maintain the instruments not to mention the added cost of equipment and spare parts. He suggests that the plant operators do not need spurious alarms caused by condition monitoring equipment which does not identify the cause or suggest a remedy; a point well taken, that identifies the need for wellconceived, real-time alarm interpretation. The reviewer also stated that the diagnostic and condition monitoring equipment will have the lowest priority for maintenance trailing safety systems, post accident monitoring systems, and process control and monitoring equipment. We suggest that the cost benefit and the maintenance prioritization of condition monitoring equipment should be examined in terms of lost availability, reduced predictability, and safety impacts of trying to operate and maintain the plant without the monitoring and diagnostics capability recommended in this report.]

\subsection{Scheduling with More Use of PRA, FMA, and More Analytical Tools}

In both new and existing facilities, after the methodology is implemented and the plant begins operation, the maintenance schedule should "learn" continuously and adapt to actual component life histories. Learning may occur in two ways. If the component is instrumented with effective degradation monitors, data may be used to predict component failure time, and this information can be factored into the failure probability distributions prior to failure and thereby accelerate the learning process. If degradation data are not available, then knowledge is increased as failures actually occur. The methodology uses PRA analysis to (a) quantify the time-dependent contributions of individual components to safety risk and availability risk, (b) assist in establishing the maximum (limit) values of risk that will be allowed from each component, and (c) thereby determine replacement/refurbishment schedules.

The methodology is broadly sketched in Appendix C, with examples of possible approaches to implementation. Further research should include the use of computer simulation for a more detailed pilot study.

In summary, the basic maintenance approach for DOE radiation facilities that must satisfy these needs in the future should stress: (1) flexibility; (2) extensive use of instrumentation in a comprehensive monitoring system; and (3) increased use of analytical tools (PRAs, FMAs, etc.) in developing maintenance tasks and schedules.

\section{CONCLUSIONS}

A better method for planning maintenance of a DOE nuclear facility can help assure that the goals of safety, predictability, and extended life can be accomplished. The development of a maintenance strategy with a flexible maintenance plan that is continually updated with the use of plant performance and hardware experience histories, will result in a condition-based maintenance program that should enhance the predictability of the plant's performance.

A dynamic maintenance program is needed and should consider the following:

1. A dynamic maintenance program for a DOE nuclear irradiation facility should be formulated during the design phase of the facility and then repeatedly modified to insure safety and predictable availability of the facility throughout its life cycle. 
2. The proposed availability of the facility to its users must be balanced between the needs of the users and the needs of the maintenance program. The confidence level with which the availability can be predicted depends on the occurrences of unanticipated outages. This prediction cannot be absolute; hence probabilities must be estimated for both availability and outages.

3. A predictive model of the operation of the facility must be developed that considers the number of users, measures of quality (flux, spectrum, etc.) at the individual irradiation stations, the need for continuous or cumulative dose, the relative urgency of the experiment or service, the consequences of deferment of service by anticipated or unanticipated outages, the expected needs for maintenance, the expected duration of maintenance actions, and the consequences of deferring maintenance actions and risking unanticipated outages. This model deals with inter-related probabilities, will become more capable as plant operating experience is accumulated, and will probably require a well-developed expert system to select the most successful courses of action.

4. Although a conventional approach toward maintenance planning using arbitrarily scheduled maintenance actions is easier to plan and implement, such an approach will incur unnecessary delays or outages caused by improper or unneeded maintenance actions. It also lacks the flexibility necessary to match the maintenance plan to lessons learned from plant operation, changes of facility mission, or end-of-life extension conditions.

5. A dynamic maintenance program requires condition monitoring, operational surveillance, diagnostics, and analysis to provide guidance for anticipatory failure-avoidance in the facility's systems. It depends heavily on feedback from operational experience and on information about the condition of the systems gained both during and after (post-use examination) the maintenance activities.

6. Provisions for monitoring and maintaining plant components must be made in the initial design of the plant and will properly exceed those usually employed for traditional plant designs. However, as one reviewer (RLC) observed, much condition monitoring information can be obtained from instruments required for plant operation or safety and does not need to be obtained from installation of additional instruments. If such provisions are made, substantial improvements in plant availability and reduction of maintenance costs and schedule interference are probable. A strategy of modular design, rapid substitution, installed spares, off-line repair, and failure diagnostics is strongly recommended, which has the added advantage of forestalling obsolescence and unavailability of parts as the plant ages.

7. Requirements of DOE orders and standards, OSHA and EPA regulations, and NRC Regulatory Guides can be met as they pertain to the operation of an irradiation facility (as distinct from a power-producing reactor) if the guidelines proposed in this document are used to direct the preparation of the facility's maintenance program. Such assurances cannot be made if traditional preparation procedures persist and prevail.

8. The cost of the proposed dynamic maintenance plan for a DOE irradiation facility is likely to be somewhat higher in its initial investment, but this difference will be 
recovered many times over by the subsequent savings in unnecessary and unproductive maintenance costs that burden the traditional scheduled maintenance approach.

9. A dynamic maintenance program requires a higher level of operator initiative and training than a traditional maintenance program and also requires continual attention to the necessary modifications of the plan.

\section{RECOMMENDATIONS}

The results of this study lead to the following recommendations:

1. A dynamic, PRA-based, risk-analysis approach should be employed in the maintenance and user scheduling process to assure adequate facility safety, provide a high probability of specific periods of facility availability for users, and defer or accelerate maintenance activities planned for accomplishment during periods of reactor shutdown.

2. The risk analysis methodology should be complemented by an assessment of available physical and personnel resources, and a cost/benefit analysis should be performed to assure that safety and availability are maintained at acceptable cost. These analyses must be updated at least as often as improvements are made in the facility or the facility's operation or mission is modified. The changing condition of the plant during its entire life cycle must also be considered.

3. The plant hardware (components, systems, and structures) should be listed and their impact on reliability should be assessed. This list should be maintained as plant improvements are made and should be divided into the following categories:

(a) hardware that is essential to assuring plant safety;

(b) instrumentation with supporting hardware and software that will enhance the monitoring capability of the facility and is needed to assess maintenance needs;

(c) modifications, upgrades, and retrofits that may be incorporated into the plant design to improve maintainability, reduce refueling time, and extend the plant life, thus impacting maintenance activities.

4. Where cost effective, the original plant design should include (a) component modularity to minimize system shutdown time, and (b) performance monitoring equipment to assist in providing data to the predictability planning methodology.

5. Further research on the proposed methodology should include the use of computer simulation for a more detailed pilot study. The first portion of such a study should be implementation of a computerized PRA of an existing or proposed facility (e.g., ANS). PRAs are commonly part of the preliminary safety analysis of nuclear facilities and could be the basis for a computerized adaptation. The second portion of the pilot study should use computer simulation to generate an operating history, component degradation and failure, and user demand for the facility to which the 
PRA applies. The interactive PRA and simulated operating history would then provide the framework for investigating details of the proposed methodology and provide a firmer basis for assessing its practicality.

\section{REFERENCES}

DOE ORDER 4330.4A, “Maintenance Management Program" (October 1990)

DOE ORDER 5480.EQ DRAFT, "Equipment Qualification for Reactor an Nonreactor Nuclear Facilities," 5-29-92

DOE ORDER 5480.30/P, "Nuclear Reactor Safety Design Criteria, Preamble" 1-19-93

10CFR5.65, "Requirements for Monitoring the Effectiveness of Maintenance at Nuclear Power Plants" (September 1991)

NUMARC 93-01 Rev 2A (DRAFT), "Industry Guideline for Monitoring the Effectiveness of Maintenance at Nuclear Power Plants," Nuclear Management and Resources Council (July 1992)

DOE-STD-1050-93, "Guideline to Good Practices for Planning, Scheduling, and Coordination of Maintenance at DOE Nuclear Facilities" (March 1993)

DOE-STD-1051-93, "Guideline to Good Practices for Maintenance Organization and Administration at DOE Nuclear Facilities" (March 1993)

DOE-STD-1052-93, "Guideline to Good Practices for Type of Maintenance Activities at DOE Nuclear Facilities" (March 1993)

DOE-STD-1053-93, "Guideline to Good Practices for Control of Maintenance Activities at DOE Nuclear Facilities" (March 1993)

ORNL/TM/NESA-93-1, "Effects of Aging on the Safety of DOE Nuclear Facilities," FWP NEKK315, R. L. Shepard, J. J. Blass, C. R. Brinkman, G. M. Slaughter, R. W. McClung, and W. J. Rowan (July 1993)

ORNL/QR/NESA-93-4, "Quarterly Progress Report for Fourth Quarter, Fiscal Year 1993," Nuclear Safety Assessment - FWP NEKK315, J. D. White , R. L. Shepard, et al.

NUREG/CR-5378, EGG-2567, "Aging Data Analysis and Risk Assessment Development and Demonstration Study," A. J. Wolford, C. L. Atwood, and W. S. Roesner, Idaho National Engineering Laboratory (April 1992)

NUREG/CR-5587, SAIC-92/1137, " Approaches for Age Dependent Probabilistic Safety Assessments with Emphasis on Prioritization and Sensitivity Studies," W. E. Vesely, Science Applications International Corporation (August 1992)

Additional references cited in this report are located at the ends of the Appendices in which details of specific portions of the work are presented. 


\section{APPENDIX $\mathbf{A}^{*}$ \\ SUPPLEMENTAL GUIDANCE FOR DOE REACTOR FACILITY MAINTENANCE PLANS}

\section{INTRODUCTION}

DOE nuclear facilities exist primarily to provide neutron and gamma irradiation sources or environments for use by scientific programs and hence their demands differ significantly from those of commercial nuclear power plants. These supplemental guidelines attempt to consider these differences without changing the demands for safety of the public and safety of the operators.

They also identify the special attention needed by these facilities to provide improved predictability, special attention to hardware that has recently been exposed to severe conditions, and the effects of aging on the facilities' useful life. Figure 3 (as shown previously in Section 6) relates existing maintenance requirements along with document changes and modifications recommended to achieve improved safety, predictability, and extension of plant life.

The basic maintenance strategy for DOE Radiation Facilities should stress: (1) flexibility, i.e., the ability to adapt to changing circumstances, (2) a comprehensive plant equipment performance monitoring system, and (3) the use of analytical tools to select the most suitable maintenance tasks and schedules.

\section{GUIDANCE}

This guidance addresses the above three maintenance strategies. The following categories of information are provided for the strategies being stressed: (a) needs and concerns, (b) approaches, and (c) priorities.

\section{A.1. FLEXIBILITY OF THE MAINTENANCE PLAN}

(a) Needs and Concerns

- $\quad$ Assurance that the maintenance is truly appropriate. Scheduled maintenance performed during each shutdown should be adjusted to reflect the conditions experienced by the plant and the particular conditions experienced during the last power cycle.

- $\quad$ Assurance that the structure of the maintenance operations for each shutdown is comprehensive and thorough. The basic maintenance tasks should be identified as a part of the initial plant maintenance plan and schedule. These basic tasks should consider and comply with all DOE and NRC requirements.

- $\quad$ Assurance that the impacts of maintenance activities on aging of hardware, mission changes, obsolescence and modernization are considered, along with a recognition that the maintenance plans will change periodically.

(b) Approaches to Assure Flexibility

*Contributed by W. J. Rowan, consultant. 
- To minimize the uncertainty associated with repair operations the designers should use modularization as a basic tenet of their designs. Through extensive use of modularization the maintenance and refueling task-times can be reduced. To assure flexibility in the planning of replacements the modularization should be tiered. This will allow the replacement of the smallest sub-assembly needed, and not force the replacement of extensive amounts of equipment to avoid in-place repair work.

- $\quad$ During each cycle use real-time information to assess the performance of the plant, the severity of conditions imposed on the hardware, and the adequacy of information collected on the previous cycle.

- $\quad$ Re-define maintenance operations for the next shutdown period while the reactor is at power by assessing the adequacy of the basic maintenance plan and identifying the additions called for by the:

- $\quad$ conditions observed during the last cycle

- $\quad$ need to incorporate additional monitoring equipment

- $\quad$ need to do special work to extend the plant life

- $\quad$ need to replace modules and subassemblies to assure that equipment needing rework, repair and/or replacement can be processed in the maintenance shop while the reactor is at power during the next cycle.

(c) Priorities Associated with the Flexibility of the Maintenance Programs The maintenance plan for the next shutdown should not be frozen without an assessment of: (1) the immediate work needed, (2) the work needed during the next few shutdown periods, and (3) the work needed to extend the plant life.

The selection of maintenance work for the next shutdown will take advantage of the analytical assessment of optimum maintenance tasks as defined by the process that is aimed at reducing the risk of needing unplanned maintenance during scheduled shutdowns or experiencing unscheduled shutdowns.

\section{A.2. MONITORING STRATEGY FOR THE MAINTENANCE PROGRAM}

(a) Needs and Concerns

Space for additional, undefined, instrumentation should be considered and incorporated wherever possible in the project's design phase.

- $\quad$ Space for instrumentation for the measurement of essential data.

- Space to accommodate instrumentation that will be needed to diagnose specific problems.

- Space to accommodate instrumentation to monitor conditions pertinent to the aging effects on the hardware.

- Space to accommodate and encourage the incorporation of advances in instrumentation and the developing use of

(b) Approach robots. 
- Incorporate provisions for expanding and upgrading the monitoring instrumentation in the plant.

- Call for an assessment of the instrumentation in each test assembly that identifies the diagnostic data that will be provided to enhance the facility information contributing to improved maintenance tasks. Include in the basic plant design requirements space in which to accommodate future use of robotic inspection and maintenance machines. In the absence of existing requirements, it is recommended that space be provided for a three-foot cube to be moved around all hardware that could require inspection and/or maintenance.

(c) Priority

The following priority assessment should be applied when allocating funds and time for maintenance beyond that which is required for safety.

(1) Support for maintenance defined as necessary due to severe conditions experienced in the last cycle.

(2) Support for tasks as called for by "The Recommended Analytical Approach for Scheduling Maintenance".

(3) Support for tasks needed to extend the life of the plant.

\section{A.3. ANALYTICAL TOOLS AND THEIR USE TO ENHANCE PREDICTABILITY}

(a) Needs and Concerns

- $\quad$ Probabilistic Risk Analysis (PRA) updating on a continuous basis

- $\quad$ Failure Mode Analysis (FMA) updating on a continuous basis

- Vendors operation and Maintenance Manuals updating on a continuous basis

- $\quad$ Power Cycle Periods should be included in the plant's experience history

- $\quad$ Refueling Period for each cycle should be analyzed for potential improvements

- $\quad$ Political demands on scheduling should be avoided

- How all of the above can be combined in a risk analysis to identify maintenance plans and schedules to improve predictability.

(b) Approach

The approach to be applied in this area is described in detail in Appendix C "A PRA-Guided Methodology for Developing an Optimized, Adaptive Nuclear Plant Maintenance Schedule Based on Safety, Availability, and User Demand."

(c) Priorities

(1) Assessment of the conditions experienced in the last power cycle compared with the FMA and PRA.

(2) Identification of maintenance tasks needing to be performed in the near-term as defined by the approach described in Appendix B.

(3) Definition of potential "political" impacts on scheduling.

(4) Definition of a revamped basic maintenance plan and schedule for the out years of operation based on the experience gained during the first two years of operation that follow the initial break-in period. 
(5) Identification of features that should be added to the plant to improve predictability and extend its life.

(6) Prioritization of the relative impacts on safety and availability of items 1 through 5.

(7) Identification of the physical, personnel, financial resources and time required to perform the various maintenance tasks.

A summary of these needs, concerns, approaches, and priorities is provided in Table A1. 
Table A1. Maintenance Factors to Increase Predictability

NEEDS

1. Flexibility in the maintenance and scheduling approach actual
2. Monitoring strategy for improving maintenance and scheduling
3. Analytical tools and their use to enhance predictability a. Assurance that the maintenance is appropriate. The

maintenance performed during each plant shut down should be adjusted to reflect the conditions experienced during the previous power cycle.

\section{CONCERNS}

a.

Assurance that
maintenance
operations during
each shut down
are comprehensive
and thorough.

and thorough

\section{APPROACHES}

a. Modularization in the basic design of the plant, its systems, and its components is essential to achieving flexibility in the maintenance plan

b. During each operating cycle use real-time info to assess the capability of the predicted maintenance and changes to the plan.
PRIORITIES

a. The maintenance plan for the next shut down period should not be fixed without an assessment of: (1) immediate work requirements; (2) work needed during the next few cycles, and (3) work needed to extend plant life.

b. The selection of work for the next shut down should take full

advantage of the assessments made in Section 3 of this table. a. Space for

additional,

undefined:

- instruments

- data processing hardware

- robotic surveillance and maintenance devices

a. Probability Risk Analysis (PRA)

b. Failure Mode Analysis (FMA)

c. Vendors' operating and maintenance manuals

d. Actual power level experienced during each cycle

e. Refueling period performance and resulting time margins
2. "Political" demands placed on the schedulers. a. Full utilization of the plant's flexible design, the data collected in the monitoring systems, and the analytical tools available for effective scheduling. See Section $4 C$ of this report, "PRA-

Guided

Methodology for Developing an Optimized

Adaptive Nuclear Plant Maintenance Schedule" based on safety, availability and user demands. a Assessment of the conditions experienced by the plant including the last power cycle

b. "Political" demands imposed by DOE

c. User requirements/demands

d. Full utilization of the physical. personnel, and financial resources; time available for maintenance tasks 
APPENDIX B*

\section{PREDICTIVE MAINTENANCE TECHNOLOGY}

\section{SUMMARY}

This appendix provides a focused description of concepts and approaches for predictive maintenance of various components in a nuclear facility. The presentation is kept general with the suggestion that the technology described may be applicable to any system/component under consideration. The material for this section was developed from several references, particularly [B6] and [B8].

The following topics are discussed.

1. Definition of terminology used in maintenance. List of technologies used in predictive maintenance (PdM).

2. Designing for effective preventive maintenance (PM). Planning, equipment, instrumentation, monitoring, and diagnostics. A typical equipment maintenance program.

3. Reliability-centered maintenance (RCM). Identifying critical components for PdM.

4. Overview of information processing methods.

5. Overview of PdM technologies:

- $\quad$ Rotating machinery maintenance.

- Instrument surveillance and calibration.

- Electrical system PdM. This includes electrical machinery, actuators, cables, batteries, and others.

- Lubrication oil analysis, wear particle analysis, and chemical analysis of various fluid flow streams.

- Maintenance of actuator systems, including control rod drives in nuclear plants, safety relief systems, spray systems, heaters, valve systems, etc.

- Maintenance of stationary components such as heat exchangers, piping, pressure vessels, etc.

- In-service inspection using nondestructive examination methods. Examples include welds, heat exchanger tubing, piping, vessels, and others.

\section{B.1. INTRODUCTION}

Safety and availability are two of the important issues that necessitate the development and application of advanced technologies for maintenance of a nuclear facility. The present trend

*Contributed by B. R. Upadhyaya, University of Tennessee. 
or maintenance in is to view plant monitoring and maintenance as part of a total maintenance program that will result in increased reliability, availability, and maintainability (RAM). Maintenance activities must be considered within the context of the total business enterprise. Good maintenance practices will also contribute to plant life "optimization" or life extension. This introductory section presents definition of terminology used in maintenance and a list of technologies used in predictive maintenance (PdM) or conditionbased maintenance.

\section{B.1.1 Definition and Terminology}

Various terms are often used by maintenance personnel and the service industry to explain different maintenance activities. Figure B1 is a flowchart showing some of the terminology and the division of the levels of activities related to maintenance (from Mercier [B6]).

Preventive Maintenance (PM) (from INPO) is periodic and predictive (condition-based) maintenance actions taken to maintain a piece of equipment within design operating conditions and extend its life.

Predictive Maintenance (PdM) is continuous or periodic monitoring and diagnosis of equipment and components in order to forecast incipient failures. PdM results are used to trend and monitor equipment performance so that maintenance can be performed prior to equipment failure.

Periodic Maintenance is work performed on equipment at a regular predetermined interval to ensure maintenance of the performance of the equipment at a prescribed level.

Reliability-Centered Maintenance (RCM) is a systematic methodology for identifying applicable and effective preventive maintenance tasks. RCM is an evaluation approach for optimizing a maintenance program.

Reliability is defined as the probability that an item will perform a required function under stated conditions for a stated period of time. The reliability is often expressed in terms of the failure probability.

Mean-Time-Between-Failures (MTBF) applies to repairable items.

Example: If an item fails 5 times in 1000 hours of operation, then

$$
\text { MTBF }=1000 / 5=200 \text { hours. }
$$

Mean-Time-to-Failure (MTTF) refers to non-repairable items. This is the average time an item may be expected to function before failure.

Example: an incandescent light bulb is typically rated for 750 hours of service.

Availability is defined as

Availability $=$ MTBF $/($ MTBF + MTTR + MTPM $)$,

where $\mathbf{M T T R}=$ Mean time to repair, and

MTPM = Mean time for preventive maintenance. 


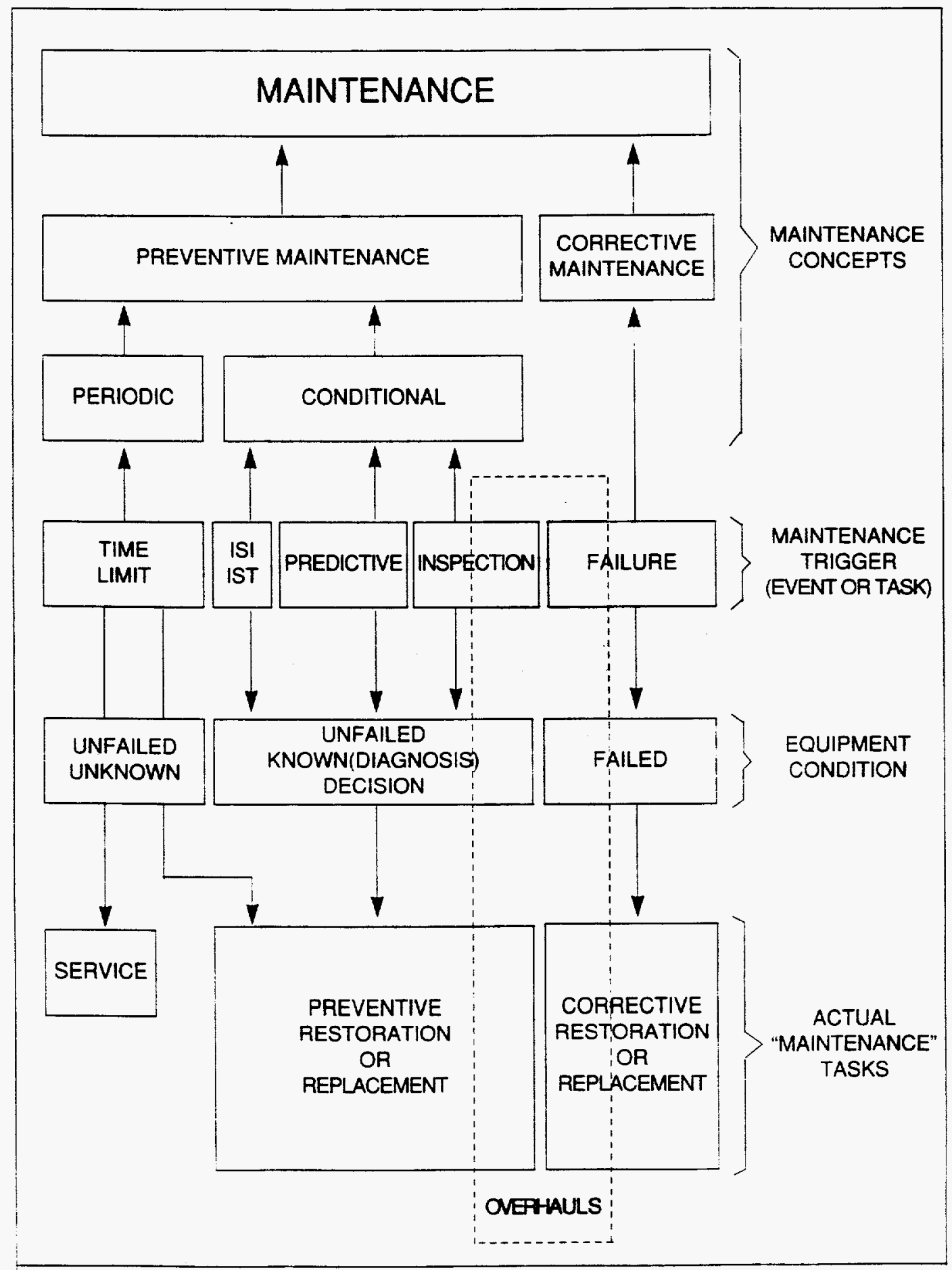

Figure B1. Maintenance terminology (after Mercier, B.6). 
Maintainability (from INPO) is a measure of the speed with which a loss of performance is detected, the fault located, repairs completed, and a check made that the equipment is functioning normally again. Improved maintainability will increase the availability. The reliability of an item should not be compromised because of an increase in maintainability.

The first priority for a nuclear facility maintenance organization is to attain the required equipment reliability; once this is achieved, a cost reduction program may be undertaken systematically. The costs incurred as a result of failures presumably decrease with increased maintenance, which in turn increases the total PM cost. This analysis must also be compared against reliability vs. PM effort. Thus, cost evaluation must consider both PM effort and reliability index.

\section{B.1.2 Analysis Methods for Predictive Maintenance (PdM)}

The primary objective of component monitoring for maintenance is to extract trending and diagnostics information from $\mathrm{PdM}$ data. Thus, a predictive maintenance program consists of continuous or periodic testing, data acquisition, and applying information processing techniques for diagnostics, decision and action. The goal is to detect incipient changes in machinery behavior and plan maintenance activities accordingly.

The following is a suggested list of analysis methods for use in predictive maintenance.

- $\quad$ Signature trending in the time and frequency domains. These include mean and RMS values, certain frequencies in the signal power spectra, RMS values at selected frequency bands, variations in magnitude and timing of events, response characteristics.

- $\quad$ Advanced digital signal processing (DSP) and signatures derived from the analysis. Examples include univariate and multivariate analyses, trends in model prediction residual sequences, coherence, cause-effect parameters and other frequency-domain signatures.

- Sequential statistical trending functions that are sensitive to incipient failures.

- Defect classification and defect parameter estimation, such as in rotating machinery analysis and nondestructive examination (NDE) techniques.

- Signal validation for instrument surveillance and calibration reduction program.

- Applied artificial intelligence methods, including neural networks and expert systems for a variety of applications.

- Linear and nonlinear dynamic regression models for forecasting residual life of plant components.

An example of a typical data trending is shown in Figure B2. The key issue is to establish the failure modes of plant components and to identify measurements that are sensitive to each type of degradation. 


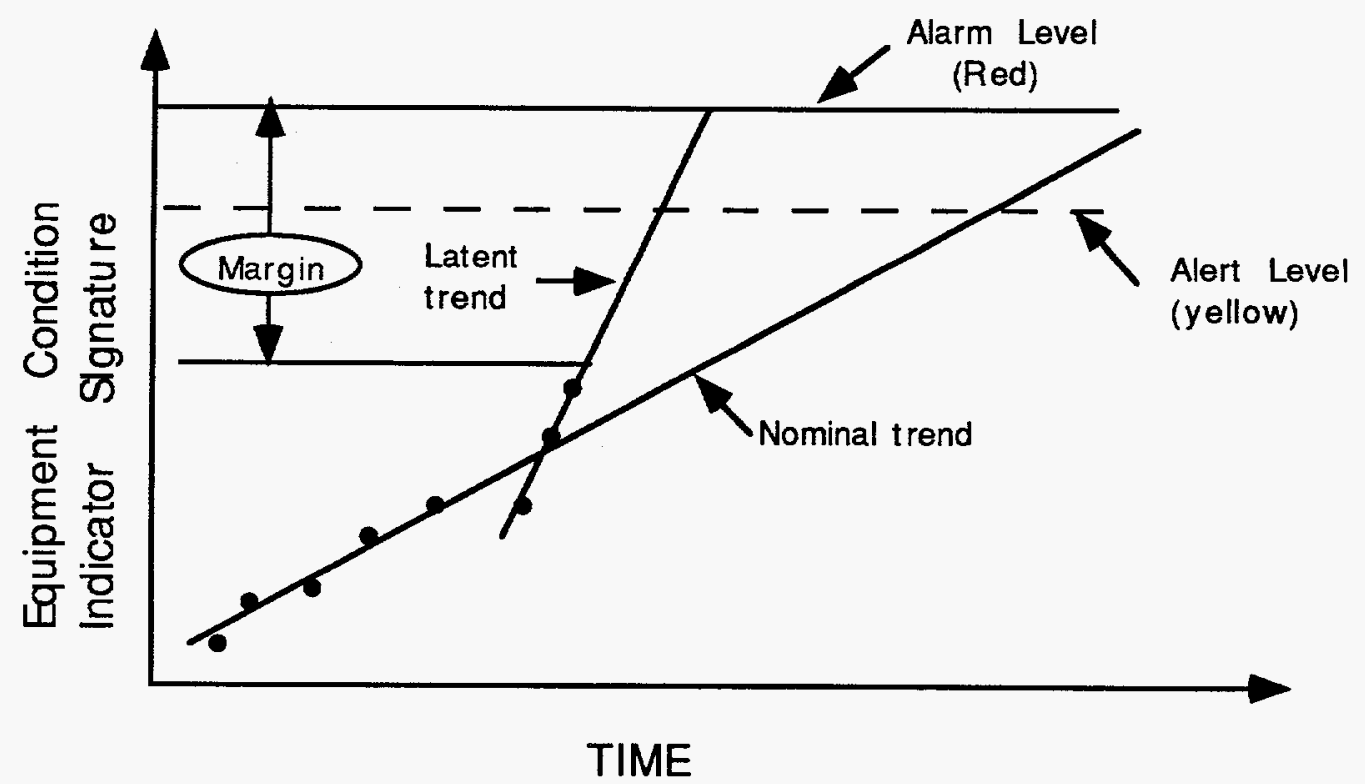

Figure B2. A typical trend plot and terminology.

\section{B.1.3 Major Areas of Maintenance}

The following areas of maintenance need to be emphasized and given consideration in the plant design phase. The degree of emphasis depends on the subsystem/component, safety and productivity goals.

- $\quad$ Rotating machinery maintenance. Vibration analysis is the primary focus.

- Instrument surveillance and calibration.

- Electrical system PdM, including electrical machinery, actuators, cables, batteries, circuits and others.

- Lubrication oil analysis, wear particle analysis, and chemical analysis of various fluid flow streams.

- $\quad$ PdM of valve systems.

- Maintenance of stationary components such as heat exchangers, piping, pressure vessels, etc.

- In-service inspection using nondestructive examination (eddy current, ultrasonic, radiography, thermography).

- Maintenance of actuator systems such as control rod drives, safety relief systems, valves, spray systems, heaters, etc.

\section{B.2. DESIGNING FOR EFFECTIVE PREVENTIVE MAINTENANCE}

This section deals with the logic path leading to the establishment of an effective preventive maintenance program. Such a program is evolutionary in nature and is allowed to change 
as increased plant operating experience is gained. The following key issues must be considered.

- A systematic identification of critical components that require continuous monitoring. Their availability is essential to the predictability of the facility. RCM or an equivalent approach may be applied to achieve this.

- A systematic evaluation of instrument placement strategy for both predictive maintenance and facility monitoring. The choice of intelligent machinery, similar to the smart sensors should be reviewed.

- $\quad$ Establishing a database that would contain maintenance history, records of sustained problems in certain plant components and subsystems, equipment replacement, manufacturer and vendor data, and other information that is relevant to plant operation and availability.

\section{B.2.1 Establishing a New PM Program}

There are three levels of maintenance that should be reviewed for critical equipment in each system.

- $\quad$ PM to control or eliminate equipment failure.

- Redesign to eliminate equipment degradation.

- $\quad$ Perform only corrective maintenance (run to failure)

or replace at regular intervals.

The three phases of a maintenance plan [B6] are now described .

A. Develop a critical equipment list

Critical equipment items are those whose failure would

- reduce or interrupt the availability of a system function affecting the reactor or personnel safety,

- reduce or interrupt unit production, or

- be expensive to repair.

B. Set maintenance targets

Use supplier information, design reviews, and equipment performance available from previous experience or from other facilities to identify failure types and their locations in the system. For each failure type, identify the root cause and the progression of the failure, the probability of failure if no action is taken,-and the safety and economic consequences of the failure. The information would be used to assess the significance of each failure mode, and the amount of maintenance effort needed to avoid the failure.

C. Develop a maintenance program based on significant failure mechanisms of critical equipment. Figure B3 provides a summary of a desired PM program. Various levels of maintenance are depicted in this diagram. Also note that equipment redesign is suggested when other alternatives do not seem to reduce the risk of failure. 


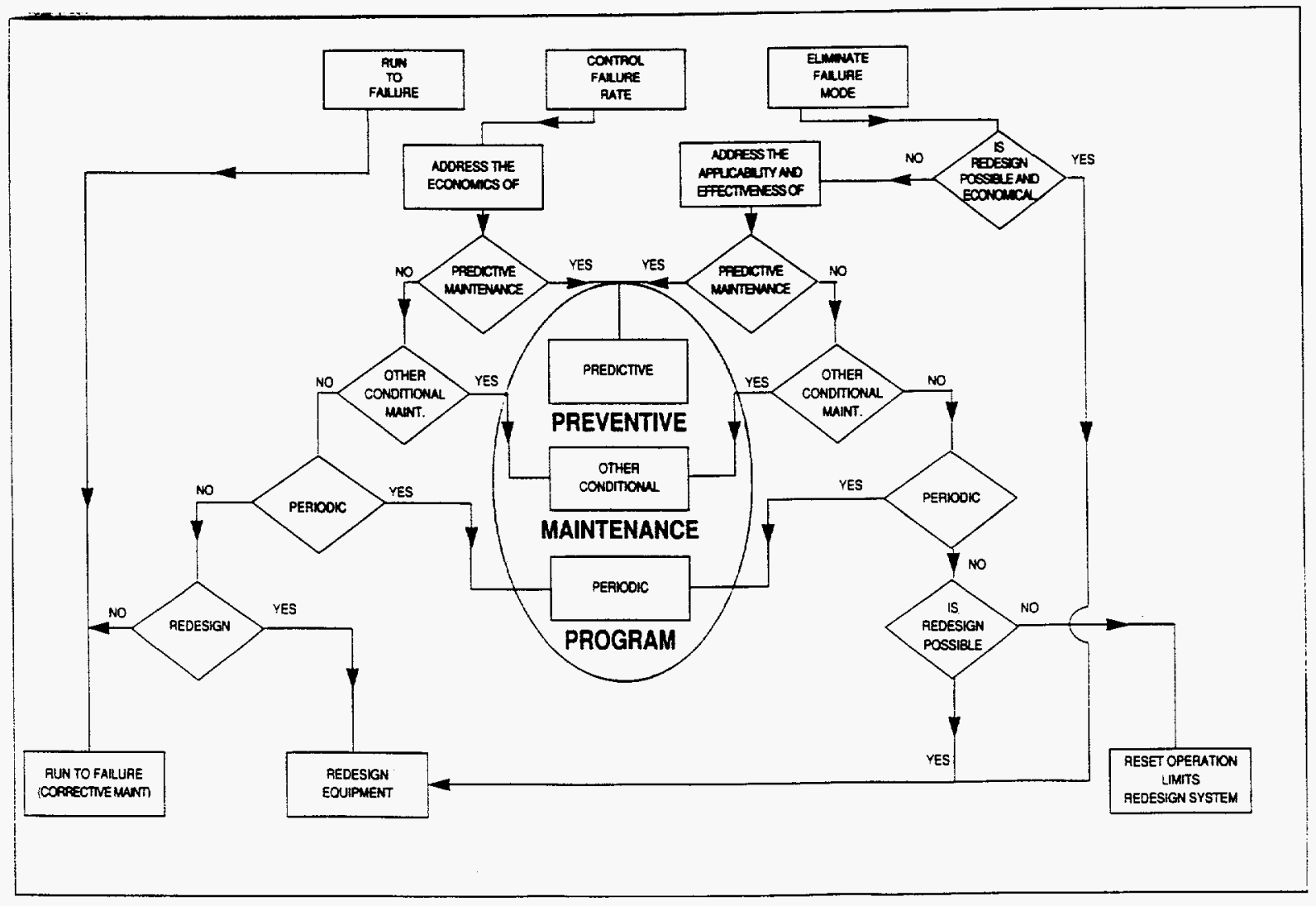

Figure B3. The PM Program: Develop the actual maintenance plan and preventive maintenance program (after Mercier, B.6). 
The maintenance strategy described is a comprehensive approach to maintenance optimization. Some of the steps outlined may not be feasible for existing facilities. But for a new facility to be built, the cost of a systematic maintenance planning and redesign (if necessary) is justified. Since PdM requires equipment monitoring, it is suggested that critical equipment be instrumented for appropriate data acquisition. This would minimize the cost of retrofits.

\section{B.2.2 Other Operational Considerations}

A PM program is evolutionary in nature, especially for a new facility. Therefore, a review of the PM program effectiveness should be made.

- $\quad$ PM efforts may have to be improved for equipment showing unsatisfactory reliability.

- $\quad$ PM efforts may have to be decreased if experience shows that the degradations are slower than anticipated.

A systematic database should be developed and updated. This must include both dynamic data used in monitoring and predictive maintenance and performance data. The latter may consist of

- maintenance activities and costs

- component failure history

- $\quad$ vendor and manufacturer performance

- $\quad$ post-maintenance problems

- $\quad$ changes in the modes of degradation (unanticipated problems)

- $\quad$ effect of operational conditions on equipment performance.

\section{B.2.3 Establishing a Predictive Maintenance Program}

Establishing and implementing a predictive maintenance (PdM) program for a process component requires a long-term planning. It requires the combination of both technical skill and management skill. A strong commitment by the maintenance department in the form of personnel and equipment cost are the necessary elements of a successful PdM program.

The following aspects should be considered:

- Management support and record keeping.

- Cost commitment to a predictive maintenance program.

- $\quad$ Minimum two-year program start-up and evaluation period.

- Assignment of dedicated and technically competent personnel.

- Adequate record keeping, database management, and information exchange.

- Data collection and analysis techniques.

- Data collection period (automated or manual).

- $\quad$ Selection of equipment to be monitored.

- On-going training of maintenance personnel.

Figure B4 is a schematic showing the technical components of a PdM program, such as for rotating machinery monitoring. 
One or more parameters that can be measured without interrupting the operation of the machinery and are sensitive to changes in operating condition.

Examples: Vibration data, motor current signatures, machinespecific process variables (such as temperature).
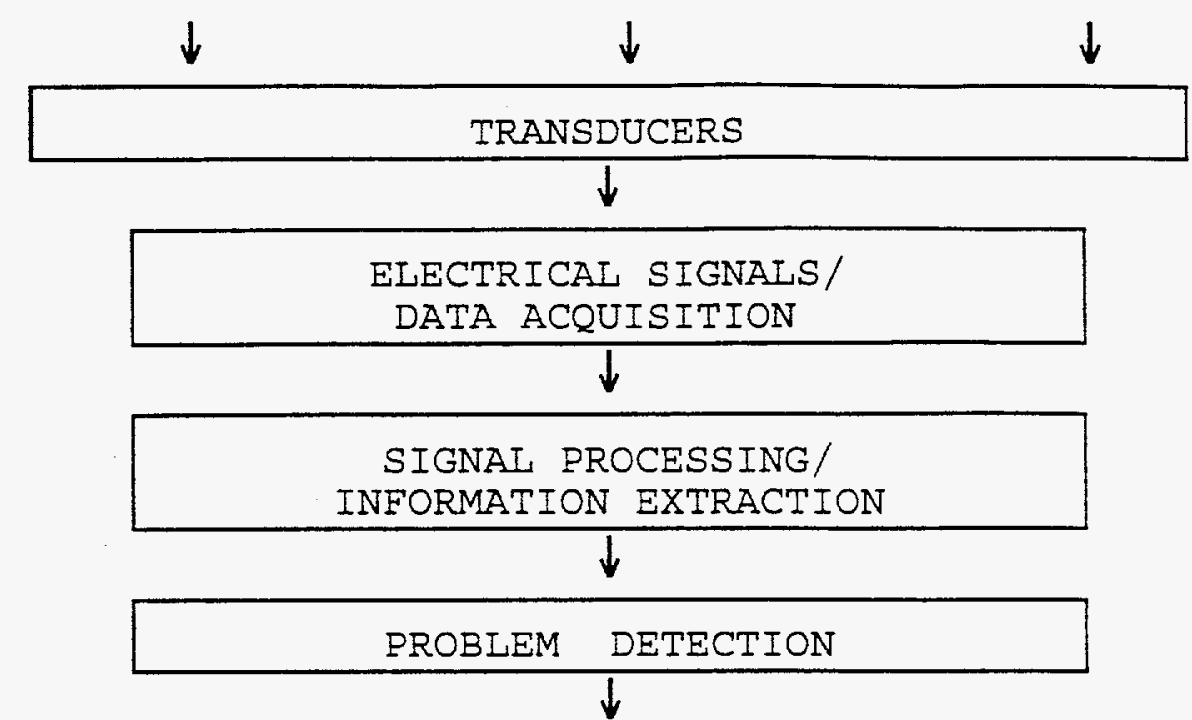
AUTOMATED/MANUAL DIAGNOSTICS

$\downarrow$

DECISION-MAKING/PLANNING

MAINTENANCE/REPAIR/REPLACEMENT

Figure B.4. Steps in a Predictive Maintenasnce Program. 


\section{B.3. RELIABILITY-CENTERED MAINTENANCE (RCM)}

\section{B.3.1 Introduction}

The following is an overview of a strategy used in preventive maintenance planning, generally referred to as Reliability-Centered Maintenance (RCM). RCM was first developed and applied in the aerospace industry, beginning in 1969-70. EPRI began to transfer the technology to the power industry in 1984. Electricite de France (EdF) is currently the world leader in the application of this technology to all of its nuclear units, beginning in 1991. EdF has found RCM to be cost effective in reducing maintenance cost and in reducing PM tasks. Likewise, an example of PM task reduction from 4600 to 1800 was reported in the U.S. at the Calloway plant. EPRI has developed an RCM workstation (1992) along with a computerized RCM technical handbook. Some case studies of applications are mentioned later in this section.

This review is aimed at understanding RCM strategy as applied to nuclear power systems; the following issues are addressed:

1. What is RCM?

2. The components of an effective RCM program.

3. Technology used in RCM development.

4. Examples of applications to the nuclear power industry.

5. Limitations and drawbacks of RCM.

A systematically developed RCM program will almost certainly help reduce operation and maintenance costs, increase plant reliability (production), and hence result in a safer plant. Thus RCM is one step towards a total maintenance plan.

\section{B.3.2 What is Reliability-Centered Maintenance?}

EPRI defines Reliability-Centered Maintenance ( $\mathrm{RCM}$ ) as a systematic methodology for identifying applicable and effective preventive maintenance tasks. Thus RCM is an evaluation approach for developing and optimizing a maintenance program. RCM utilizes a decision logic tree to identify the maintenance requirements of equipment according to the safety and operational consequences of each failure and the degradation mechanism responsible for the failure.

A successful RCM program is expected to accomplish the following objectives:

1. Ordering of equipment for maintenance according to their importance, safety implications of their failure, and cost savings.

2. Proper allocation of maintenance tasks.

3. Improved reliability of equipment and overall system safety.

4. Increased production and long-range economic benefit.

\section{B.3.3 Components of an Effective RCM Program}

It is important to realize that if an RCM program has to incorporate various components in a large system, such an analysis requires considerable effort. A more focused approach is to 
restrict attention to the development of a maintenance strategy for the components comprising a few key plant systems. The components for evaluation may include valves and actuators, electric motors, pumps, electrical cabling, heat exchangers, instrumentation, etc.

The following steps are generally followed in developing a reliability-centered maintenance program:

1. Information collection-This involves developing a system design database, and acquisition of operational, maintenance, and failure data.

2. Identification and partitioning of system boundaries and interfaces, and separation into functional subsystems.

3. Analysis of requirements-This includes defining system functions and functional failures, and identifying dominant failure modes (those that occur frequently or whose consequences has a strong safety implication).

4. Preventive maintenance task development-Using a decision logic tree, specify a preventive maintenance task, a test, (for example, additional data acquisition from diagnostic sensors), or a design change. The latter goes beyond just a PM program. This analysis may also conclude that the failure can be accepted.

5. Incorporating the RCM recommendations into the actual maintenance procedures. Additionally, these can be used for decision making at different levels.

\section{B.3.4 Technology Used in Developing an RCM Program}

Figure B5 is a schematic showing the basic steps and analytical tools used for establishing a general RCM program. The following are some of the techniques used in the analysis.

1. Failure modes and effects analysis (FMEA).

2. Fault tree analysis to understand the cause and probability of component failures.

3. Digital signal processing and statistical analysis. These are useful for component trend monitoring, detection of incipient failures, and for estimating residual life of equipment. This is not a routine part of an RCM analysis.

4. Logic tree analysis for maintenance task selection. The logic tree analysis produces recommendations for PM of components that are declared to have critical failure modes. The criticality of failure modes is related to their impact on safety, availability, and maintenance costs. 


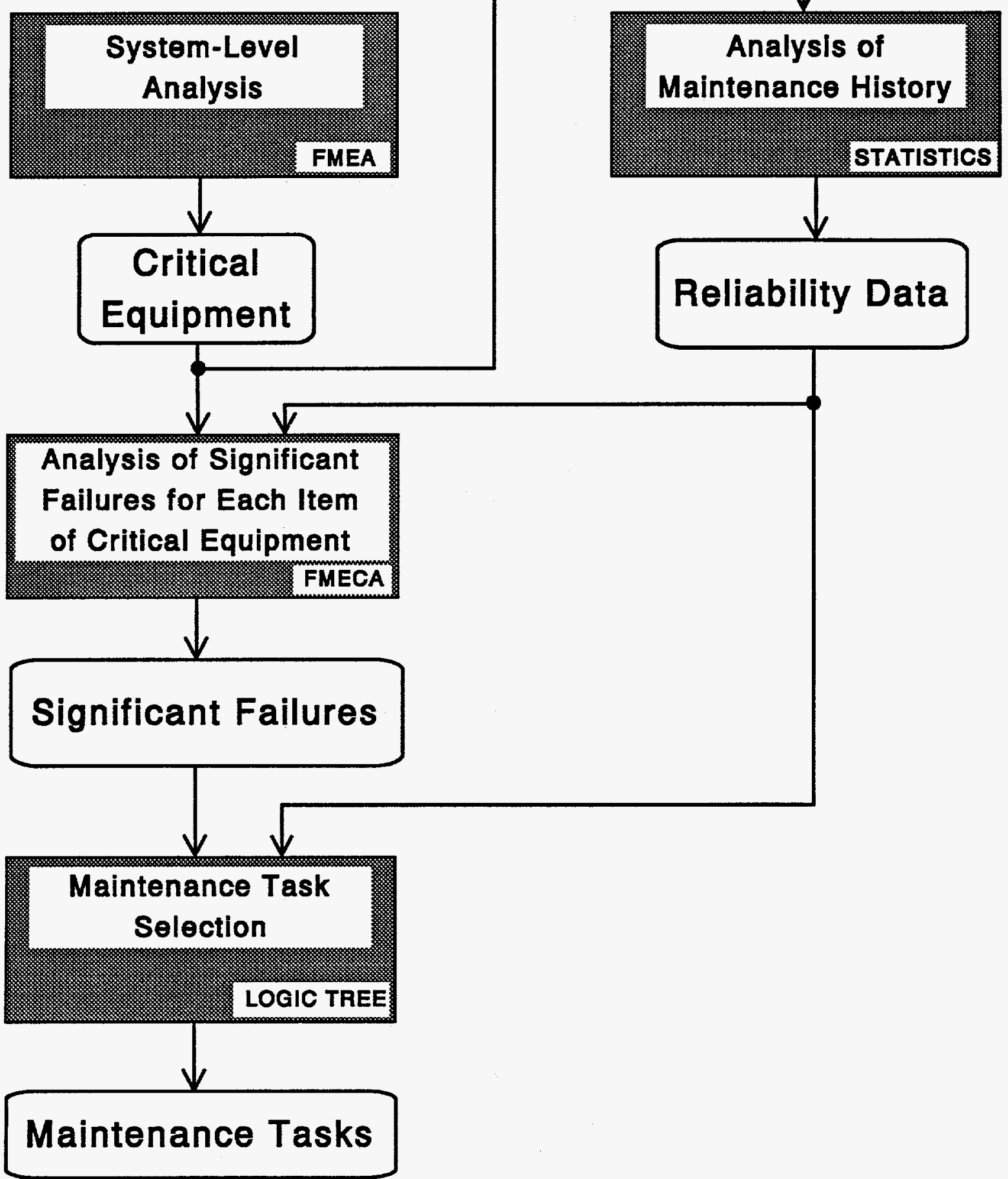

Figure B5. Basic Steps and Analytical Tools Used for Establishing a General RCM Program. 


\section{B.3.5 Applications in the Nuclear Industry}

The following are examples of applications of RCM in the nuclear power industry:

1. RCM program at San Onofre, Southern California Edison Co. The system for analysis included radiation monitoring, chilled water- normal HVAC, fire protection, feedwater, condensate, service air system, saltwater cooling system, chilled water emergency HVAC, full-flow condensate polisher, d-c electric system, chemical and volume control system, emergency diesel generators, auxiliary feedwater system.

2. Turkey Point Units 3 and 4, Florida Power and Light Co. Pressurizer spray system, heater banks, pressurizer power-operated relief valves, charging, let-down and control valves in the CVCS.

3. The program at McGuire Nuclear Station, Duke Power Company.

4. RCM program at Electricite de France nuclear and fossil generating systems.

\section{B.3.6 Limitations of RCM}

$\mathrm{RCM}$ is not a substitute for correcting design deficiencies in a plant. Inadequacies in maintenance training and analysis techniques cannot be directly addressed by RCM. Preventive maintenance task details cannot be specified by the RCM. It is one part of a facility's effort to improve the availability, reliability, and safety of a plant. Its potential can be realized only if other components of the total maintenance program are sound.

\section{B.4. INFORMATION PROCESSING TECHNIQUES USED IN PREDICTIVE MAINTENANCE}

This section provides an overview of both classical and modern information techniques available to maintenance engineers for applications in a predictive maintenance program. Several techniques can be readily implemented using commercially available digital signal processing (DSP) software systems. The vendors of PdM equipment have developed software systems that are compatible with their products. The tools available for information processing may be classified into two broad categories.

- Digital signal processing: classical and modern techniques.

- $\quad$ Applied artificial intelligence methods.

These technologies are briefly reviewed in this section.

\section{B.4.1 Digital Signal Processing (DSP)}

Signal processing deals with the analysis of stationary and nonstationary measurements acquired from sensors used for control, machinery diagnostics and safety system monitoring. DSP is the technology of analyzing signals that are digitized or sampled at a specified sampling rate. The primary goal of DSP is to extract information about the operation of a component or a system with applications to monitoring, diagnostics, control, predictive maintenance, estimation of performance-related parameters, pattern recognition, 
sensor verification, and others. The DSP is used in every industry, from aerospace and communication systems to medical diagnostics.

The key to the applications of this technology is to have the ability to acquire quality data from process sensors. The steps in data acquisition consist of

1. Sensor placement and its output verification.

2. Signal preconditioning such as filtering and amplification.

3. Signal recording. This is performed digitally in most applications and requires the choice of a proper sampling rate.

4. Data qualification and storage.

Figure B6 shows the schematic of a digital data acquisition system where the signals are sampled and stored in a computer (such as a PC or a workstation). 

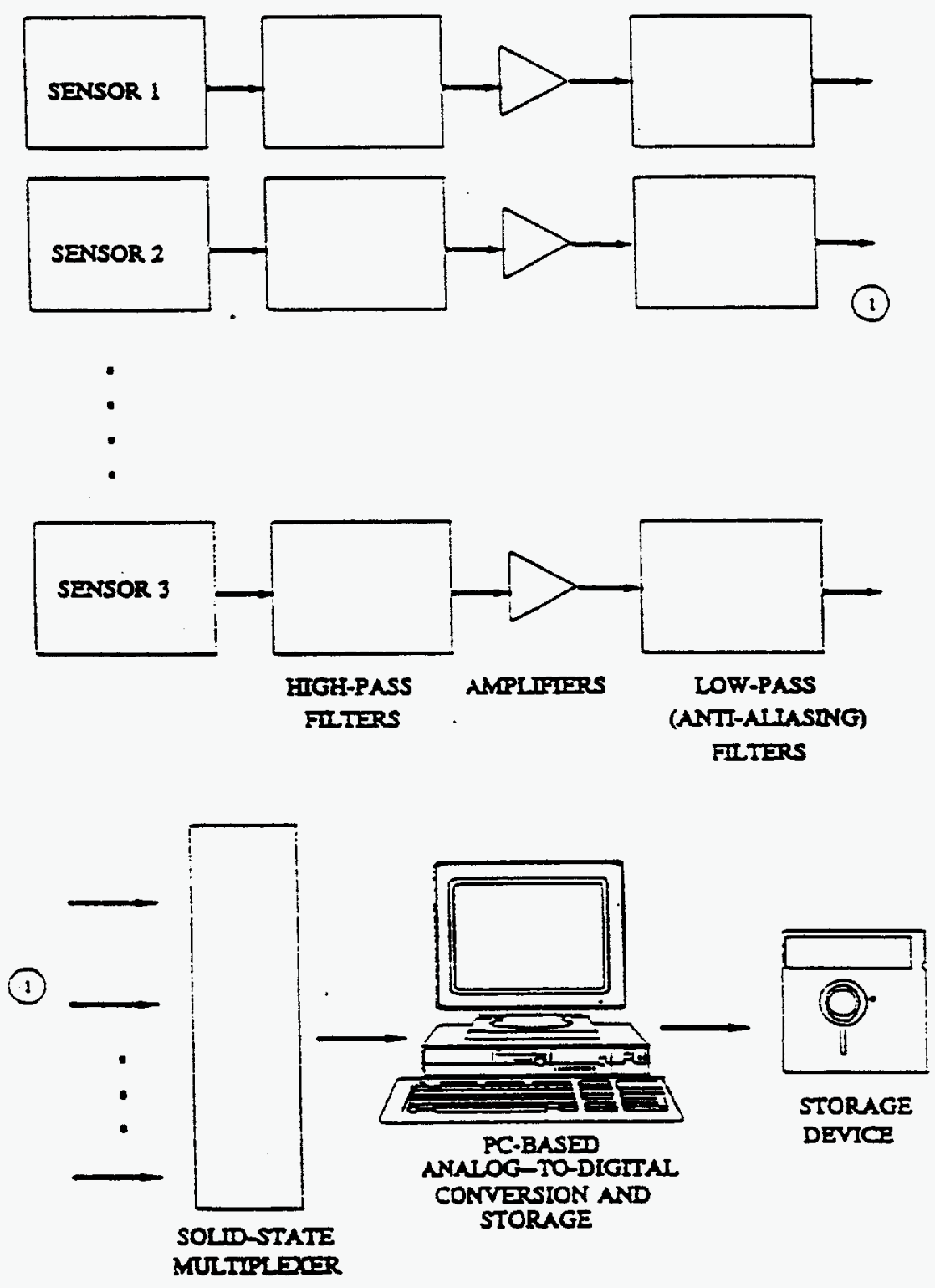

Figure B6. Data Acquisition System Showing Signal Conditioning Devices, Signal Multiplexer, and PC-based A/D Conversion. 


\section{B.4.2 Time-Domain and Frequency-Domain Signatures}

A random signal is said to be stationary if its statistical properties do not change as a function of time. Various time-domain signatures may be computed for stationary signals using time averages. Examples of time-domain signatures are

1. Mean, variance and root-mean-squared (RMS) values.

2. Amplitude probability density function.

3. Autocorrelation and cross correlation functions.

The information in a random signal can also be described by transforming the signal to the frequency domain. This form of signal compression provides insight into the signal bandwidth characteristics, oscillatory nature of system responses and frequencies related to the vibration of rotating machinery and other plant components. A computationally fast finite Fourier transform algorithm, called the fast Fourier transform (FFT), is a popular tool used in this classical technique. The following frequency-domain signatures are generally estimated using the FFT.

1. Auto-power spectral density (APSD) of a signal.

2. Cross-power spectral density (CPSD) between two signals. (magnitude and phase).

3. Coherence function between two signals.

4. RMS values of a signal at different frequency bands.

Both time- and frequency-domain signatures may be used for trending the behavior of a system component. The trend data can be used for system prognosis such as estimating the residual life of equipment and for alerting the operator of an incipient failure. More advanced techniques may be used for diagnosing the cause of changes in the system and for estimating certain performance related parameters.

\section{B.4.3 Modern Methods and Emerging Technologies for Information Processing}

The accurate diagnostics of system components or instrument behavior requires a combination of basic data analysis and a causal relationship among a set of measurements. The latter is useful for tracking process signals, improved detection of the cause and source of anomalies, and early detection of incipient failures. These needs have resulted in the emergence of new techniques and improvements in the existing techniques.

The following techniques are being implemented to solve problems related to component diagnostics, predictive maintenance and system prognosis.

1. Univariate and multivariate time-series modeling.

2. Dynamic multiple regression models for residual life estimation.

3. Statistical pattern recognition techniques.

4. Sequential statistical trending.

5. Expert systems.

6. Artificial neural networks. 
These techniques may be applied to a variety of problems in predictive maintenance.

- Signal validation and plant-wide monitoring.

- Determination of cause-and-effect relationship among a set of signals.

- Identification of transients.

- $\quad$ Classification of vibration data.

- $\quad$ Automated diagnostics using NDE data.

- Estimation of residual life of plant components.

- Estimation of chemical composition of flow streams.

- $\quad$ Expert systems for automated diagnostics using time waveforms or frequency-domain signatures.

- PdM data trending and detecting incipient changes in system/component behavior.

\section{B.5. OVERVIEW OF PdM TECHNOLOGIES}

The development of an effective predictive maintenance program can be achieved in many cases by the proper implementation of a broad spectrum of available technologies. A summary description of the following PdM technologies is given in this section.

1. Rotating machinery monitoring and diagnostics.

2. Instrument surveillance and calibration verification.

3. Monitoring and diagnostics of valve systems.

4. Electrical system monitoring.

5. Lubrication oil analysis and wear particle analysis.

6. In-service inspection using nondestructive examination (NDE) methods.

\section{B.5.1 Rotating Machinery Monitoring and Diagnostics}

One of the most effective predictive maintenance techniques for rotating machinery is to monitor their vibration characteristics. Vibration of rotating machines is caused by shaft imbalance, misalignment, bent shaft, mechanical looseness, instability in journal bearings, defects in rolling-element bearings, and faults in gearboxes due to gear wear.

It is possible to diagnose the various problems by a detailed analysis of signals from displacement, velocity, and acceleration transducers, in the frequency domain. The variation of the energy in a vibration signal at different frequency ranges may be related to specific problems in a rotating machinery. Machinery for which routine vibration trending is preformed include: pumps, motors, turbines, generators, gearboxes, valve systems, crushers, blowers, compressors, fans, bearings, and drives.

Modern vibration monitoring is performed using in-situ measurements and portable data loggers. Both time-domain and frequency-domain techniques are used for analysis and diagnostics. The interval of routine monitoring depends on the type of machinery. One of the goals of predictive maintenance by vibration monitoring is to identify incipient faults in systems and use this information for scheduling maintenance and determine the useful life of an equipment. 


\section{B.5.2 Instrument Surveillance and Calibration Verification}

Since the incident at Three Mile Island unit 2, (TMI-2) computerized plant status display, implementation of human factors in control room design, and plant monitoring systems have seen a large growth. The availability of plant information, especially during an accident and recovery phase is very critical. Thus, continuous surveillance of instrument channels serves many purposes, including reliable control actions, improved operator decision making and proper actions of protection (safety) systems. This technology also has other implications such as reducing challenges on control systems, minimizing plant downtime, and for predictive maintenance advising. Use of signal validation and instrument system knowledge base may also be used for reducing calibration of redundant instrument channels.

Surveillance of instrument channels is generally performed using well-defined routine tests and in some instances using recently developed signal validation technology. Distinction must be made between checking of individual channels for their integrity and crosschecking of similar channels for their relative variation.

\section{B .5.3 Monitoring and Diagnostics of Valve Systems in Power Plants}

Periodic monitoring of various types of valve systems is an important operational issue in power generating stations and process industry. In nuclear power plants reliable operation of valve mechanisms is essential to assure proper performance of control and safety systems. Plant availability is also greatly impacted by problems associated with valve operations. It was estimated that in nuclear plants valve-related problems cost U.S. utilities about $\$ 100$ million per year in loss of plant availability and up to 30 per cent of the industry's annual maintenance budget. In fossil plants, load cycling duty causes high stresses to plant components. This has generated many problems in boiler start-up system valves. About 20 per cent of unscheduled outages in nuclear power plants are valverelated.

Extensive research and development efforts are being pursued to improve valve monitoring and diagnostics method. The common types of valve operator include Motor-Operated Valves (MOVs), Air-Operated Valves (AOVs), Solenoid-Operated Valves (SOVs) and Check Valves. Valve operators vary in size depending on the type of service. In many instances special measurements are performed to monitor valve actuators for predictive maintenance.

\section{B.5.4 Electrical System Monitoring for Predictive Maintenance}

Condition monitoring of electrical systems includes both stationary components (such as cables, instrument channels, etc.) and rotating dynamic components (such as motors, generators, actuators, etc). Short-term operational, as well as long-term aging of electrical components and their maintenance, is a very important issue in both high-flux nuclear facilities. Some of these are addressed by the Nuclear Regulatory Commission's NPAR (Nuclear Plant Aging Research) program.

The tests for integrity of electrical circuits and insulation of electrical components, generally compare test data with data from baseline condition for a similar system or circuit. Several commercial equipment are available for performing these tests. 
Advanced technologies are now available for detecting, isolating and quantifying faults in electrical systems, and for establishing their general condition even when a fault does not exist. The problems related to electrical circuits include bad connections, ground faults, deteriorated cables, internal shorts, moisture intrusion, low insulation resistance, impedance imbalance, and others.

\section{B.5.5 Lubrication Oil Analysis and Wear Particle Analysis}

The analysis of lubrication oil is performed to monitor the quality of the oil, to determine the percent of contaminants such as water and process material, and for the presence and quantity of mechanical wear particles. Lubricants are tested for quality, additives and contaminants and various wear particles.

Lube oil analysis must be performed periodically as part of a preventive maintenance program. Annual savings of up to $\$ 250,000$ have been reported because of an oil analysis program in typical industrial plants. Condition-based oil change is more effective, both for economic savings and minimizing plant downtime. Almost $50 \%$ of all bearing failures are the result of improper lubrication or contamination. Component failures, such as corrosion, abrasion, fatigue and others, can be detected using wear particle analysis. Both on-site and off-site analysis methods are used. On-site oil analysis has the advantage of giving immediate feedback to maintenance personnel. Off-site analysis offers more sophisticated tools and the utilization of a larger lube oil technology database.

\section{B.5.6 Nondestructive Examination (NDE) Technology}

Nondestructive Examination (NDE) is the process of measuring some vital characteristic of a component without rendering the part unfit for continued service. Some examples of NDE are flaw detection in steam generator (heat exchanger) tubing, detection of intragranular stress corrosion cracking, dental x-rays, fetal monitoring using ultrasonic probes, CAT scan, MRI, PET scan, detection of flaws in welds, aircraft engine support integrity. Because of high pressure, temperature and radiation exposure of certain components in a nuclear facility, continued in-service inspection, (ISI) has become a necessity. The need for periodic ISI of certain nuclear plant components has resulted in a new requirement and was published in 1970 as Section XI of ASME Boiler and Pressure Vessel Code, "In-service Inspection of Nuclear Reactor Coolant Systems." The most desirable type of examination to perform on material is a nondestructive examination. Nondestructive Examination includes a variety of different methods that are used to determine the physical soundness of a specimen without altering or impairing its usefulness. NDE is a basic industrial tool for assuring quality and reliability.

The following NDE techniques are used in industrial testing.

- Visual Examination

- $\quad$ Penetrant Testing

- $\quad$ Magnetic Particle Testing

- Ultrasonic Testing

- $\quad$ Eddy Current Testing

- $\quad$ Acoustic Emission Testing

- Radiographic Testing

- Thermographic Testing

- Compositional Analysis 


\section{REFERENCES}

B.1. "Experts Address Cost Spiral Causes and Fixes," Nuclear News, pp. 29-31, January 1991.

B.2. R. S. Hilligoss, "Maintenance: Business Opportunities of the 1990s," Maintenance Technology, pp. 36-39, 1991.

B.3. J.W. Flude and J.R. Nicholas, "Predictive Maintenance Primer," EPRI Report NP-7205, April 1991.

B.4. P.D.T. O'Connor (Editor), "Reliability Engineering," Hemisphere Publ. Corp., New York, 1988.

B.5. J. P. Gaertner et al, "Demonstration of Reliability-Centered Maintenance," Vol. 1,2,3, EPRI Report NP-6152, 1989.

B.6. J. P. Mercier, "Advanced Nuclear Power Plant Maintenance," EdF, Editions Kirk, France, 1993.

B.7. B.R. Upadhyaya, M. Naghedolfeizi and B. Raychaudhuri, "Residual Life Estimation of Plant Components," Proc. Predictive Maintenance Technology National Conference, Dallas, Texas, November 1993.

B.8. B. R. Upadhyaya, "Preventive Maintenance Technology, "A Training Manual prepared for the EPRI NDE Center, 1994. 


\section{APPENDIX C}

\section{A PRA-GUIDED METHODOLOGY FOR DEVELOPING AN OPTIMIZED, ADAPTIVE NUCLEAR PLANT MAINTENANCE SCHEDULE BASED ON SAFETY, AVAILABILITY AND USER DEMAND}

\section{C.1. INTRODUCTION AND OBJECTIVE}

Safety and availability of a nuclear facility are strongly dependent upon an effective maintenance schedule. For a new facility the establishment of a schedule is necessarily based upon equipment manufacturers' recommendations and/or data from similar components in other facilities. After the plant goes into service, this initial schedule may need modification if actual component life differs significantly from expected. Facility owners and managers may benefit from "smart," dynamic surveillance techniques and maintenance procedures that inherently evolve with the plant and maintain required safety margins and assure expected plant availability.

The U.S. Department of Energy (DOE) initiated the Nuclear Safety Self-Assessment Program for purposes of developing new plant aging and maintenance methodologies for DOE research facilities. There is a growing body of international literature describing enhanced maintenance approaches (e.g., Refs. C.1-C.9) and use of probabilistic risk analysis (PRA) to quantify risk as a guide to maintenance in commercial plants (e.g., Refs. C.10-C.23). Research facilities commonly have an additional operating goal of providing services to users on a predetermined timetable for small-angle scattering experiments, isotope generation, etc. The methodology described here endeavors to (a) provide a flexible framework within which to apply PRA-based maintenance techniques, (b) outline a generic approach applicable to research facilities, and (c) go a step beyond maintenance, safety and conventional availability considerations in order to integrate user-demand into a dynamic, adaptive maintenance/user schedule that is continuously tuned to changing conditions of the plant and the demands placed on it.

The methodology is broadly sketched here, with examples of possible approaches to implementation. Further analysis is needed to tailor it to specific plant operations, as well as for proof of principle.

\section{C.2. DESCRIPTION OF METHODOLOGY}

The proposed methodology consists of five principal processes, shown in the functional flow chart of Figure $\mathrm{Cl}$ and summarized here:

- Component condition data: encode data that provide historical and/or degradationpredicted failure rates for plant components that are to be addressed in the maintenance schedule.

*Contributed by O. L. Smith, ORNL 

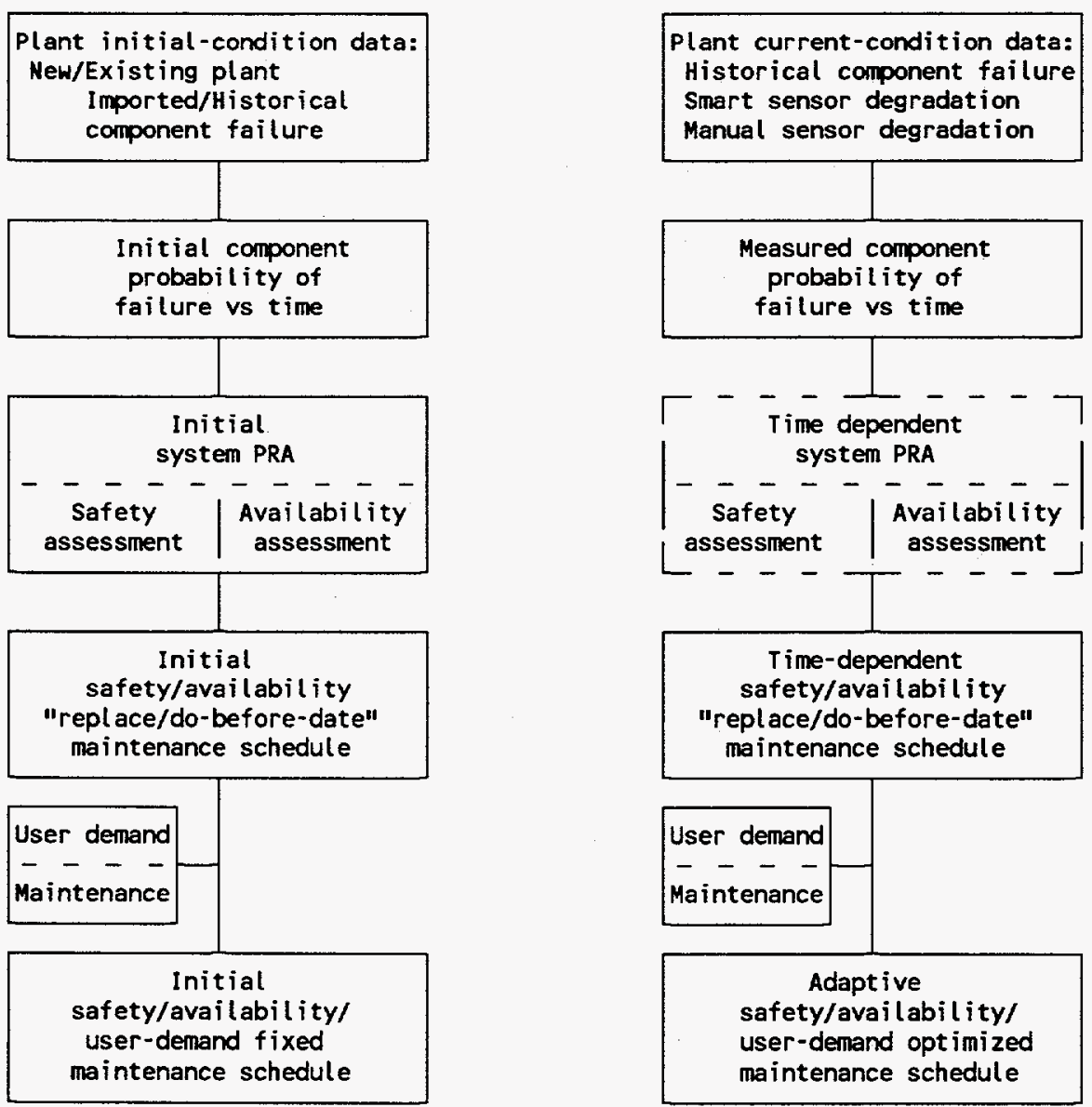

Figure $\mathrm{Cl}$. Flow chart of the methodology. 
- $\quad$ Failure probability distributions: transcribe data into curves depicting component probability of failure versus time.

- $\quad$ Probabilistic risk analysis (PRA): use failure distributions in PRA to quantify the impact of component failure on safety and availability.

- Time-dependent safety and availability maintenance schedule: translate PRA assessment into a dynamic maintenance schedule to keep safety and availability risks below prescribed limits.

- Adaptive safety, availability and user-demand maintenance and operating schedule: fold user demand into schedule to provide an integrated and optimized safety-, availabilityand user-sensitive maintenance and operating schedule that evolves with the plant and the user demands placed upon it.

Initial values (left column of Figure $\mathrm{C1}$ ) for a new facility are imported from outside sources or based on engineering judgement. For an existing facility, initial values may come from historical files of the plant, possibly supplemented with outside sources or engineering judgement where operating history does not provide adequate data.

In either type of facility, after the methodology is implemented and the plant operates (right column of Figure $\mathrm{C1}$ ), the maintenance schedule continuously "learns" and adapts to actual component failure histories, and the initial data are phased out of the evaluation. Learning may occur in two ways. If the component is instrumented with effective degradation monitors, data curves may be extrapolated to component failure time (Figure C2), and this information can be factored into the failure probability distributions prior to failure and thereby accelerate the learning process. If degradation curves are not available, then learning occurs as the failures actually occur.

The methodology uses PRA analysis to (a) quantify the time-dependent contributions of individual components to safety risk and availability risk, (b) assist in establishing the maximum (limit) values of risk that will be allowed from each component, and (c) thereby determine replacement/refurbishment schedules. So long as a facility does not experience events uncounted in the initial PRA, routine rerunning of the PRA to monitor safety and risk factors may be unnecessary; the time dependent PRA is therefore shown in dashed outline in Figure $\mathrm{C} 1$ to indicate possible optional rerun. The methodology is discussed further and illustrated in the following sections.

To demonstrate the generation of component failure data and resulting probability distributions and the transition from initial to actual data (top two processes of Figure C1), two generic illustrations are given here, the first in which the components are found to have a shorter meanlife than expected, and the second in which the components have a longer meanlife. Actual forms of failure rate and distribution functions depend upon specific components and environments. 


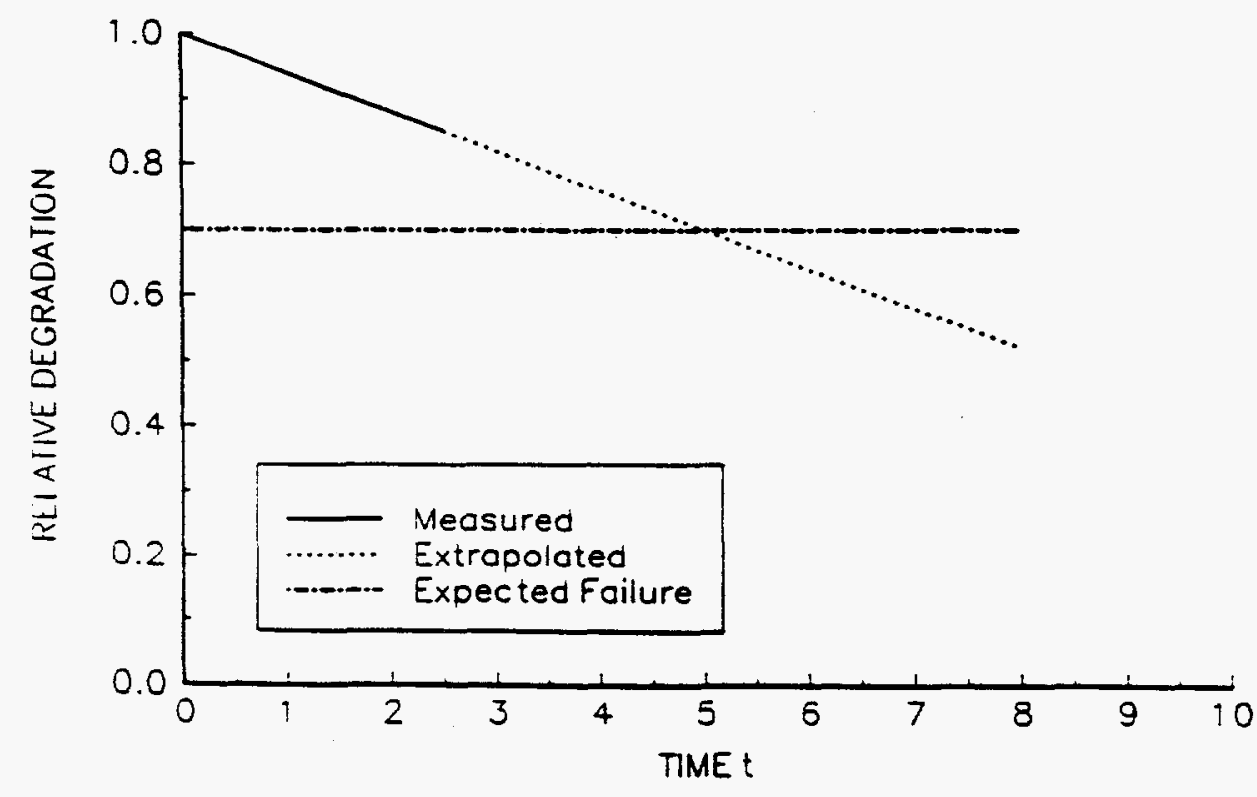

Figure C2. Data from component degradation instrumentation are extrapolated to predict time of component failure.

\section{C.2.1. Component Condition Data and Failure Probability Distributions}

In the first example, initial failure data for plant primary system components of Type 1 are based on histories of ten components in similar facilities. These failed at the rates shown by the normalized frequency function, $\mathrm{f}$, in Figure $\mathrm{C} 3 \mathrm{a}$, left scale. Integration of the failure frequency provides the initial probability distribution, $D$, that a component will fail at a time less than $t$ (Figure C3a, right scale). From this curve, the expected mean-time-to-failure $(\mathrm{D}=0.5)$ is 6.4 time-units.

Using probability distributions for all components of interest, the facility management determines from PRA analyses (described below) that the limit probability of failure for Type 1 components is to be $D=0.6$, and hence from Figure $C 3 a$ the initial maintenance schedule calls for the components to be replaced after 6.8 operating time-units.

Subsequently, each time a Type 1 component fails, it is added to the failure function. Figure $\mathrm{C} 3 \mathrm{~b}$ shows the operational evolution of this function. The curve labeled " $10 \mathrm{comp}$ " is the initial 
frequency distribution for 10 components in similar environments; the curve labeled " $10+1$ comp" is after one in-plant component failure; "10+7 comp" is the distribution after 7 in-plant failures, etc. The peak of the frequency function gradually shifts to the left over time, indicating that the actual operating life of Type 1 components in this plant is shorter than expected. The resulting shift in probability distribution is shown in Figure $\mathrm{C} 3 \mathrm{c}$. If the facility management is to limit probability of failure to $\mathrm{D}=0.6$ for safety and availability purposes, then the evolving failure history systematically reduces the replacement schedule from 6.8 time-units to 5.5. If the half-life is short, the evolution should occur quickly. At the other extreme, if the halflife is long, the evolution may still be in progress when the plant reaches end-of-life.

In this example actual component failures are given equal weight with the initial components in generating the evolving failure frequency function. Transition to the operating data can be accelerated by reducing the weighting of the original failure data as the actual data are folded in.

In the second example, the postulated primary system Type 2 component has a probability distribution function initially based on failure rates of six components in a similar environment (Figure C4a). The expected meanlife is 5.2 time-units. On the basis of PRA analysis, the facility management determines that the failure probability of these components will be limited to $\mathrm{D}=0.65$, indicating an initial replacement schedule of 6 time-units.

After the plant begins operation, no in-plant failures of these components occur during the first 6 time-units, suggesting that the component meanlife may be longer than expected. The methodology allows the maintenance schedule to learn the longer meanlife. As a component ages, it will in general move up its probability of failure curve until the risk limit is reached. The component then is replaced. This defined "failure" is greater than the initial halflife. Adding it into the failure distribution will translate the failure probability to the right, as in Figure C4c, and contribute to learning the longer meanlife. To the extent that subsequent failures repeat this sequence the learned meanlife will grow until it stabilizes at the actual meanlife. 
(a)

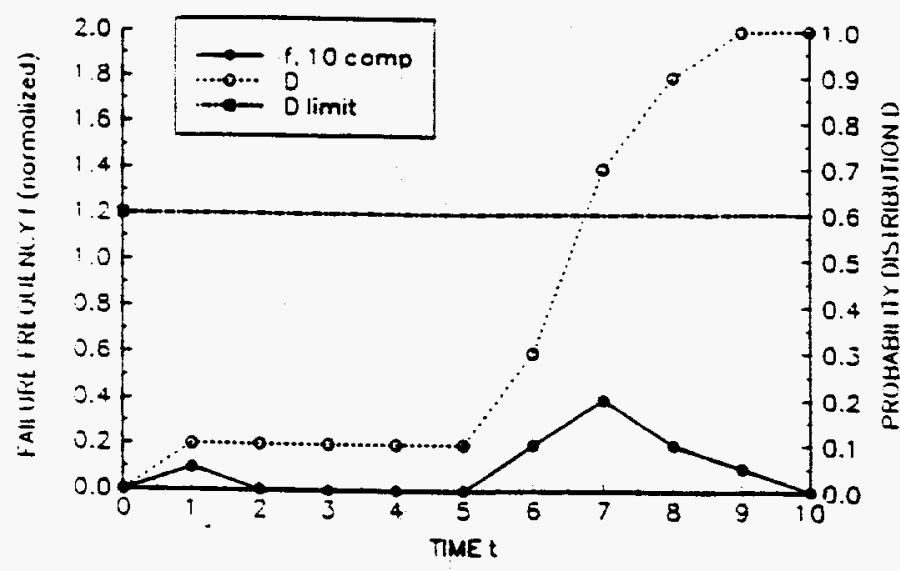

(b)

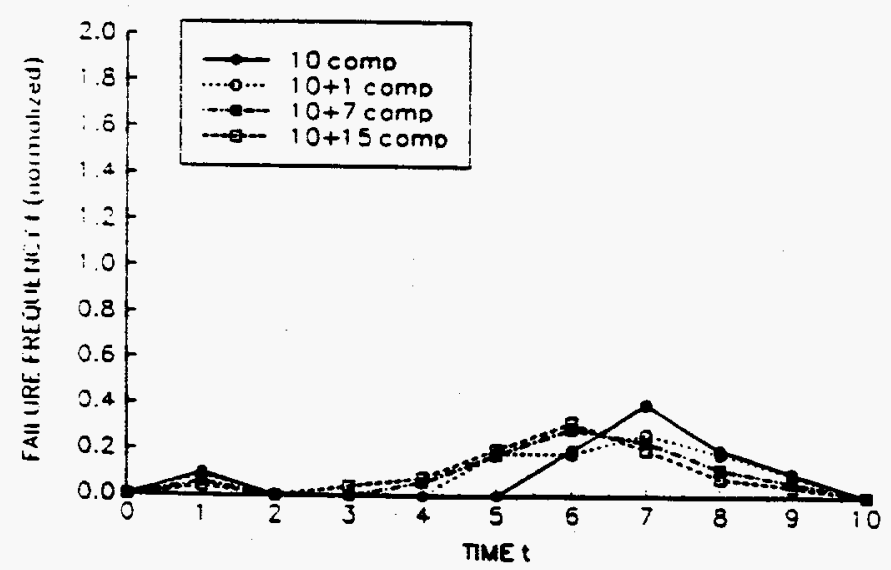

(c)

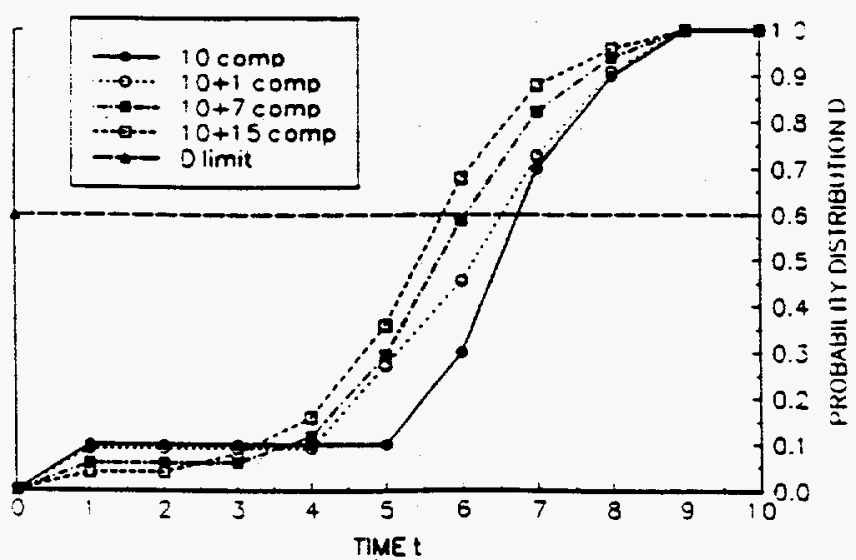

Figure C3. Failure frequency and probability distribution when meanlife of components in plant proves to be shorter than expected. (a) Initial data from 10 similar components in other facilities. (b) Evolving failure frequency as in-plant components fail; "10+i" indicates 10 original components plus $\mathrm{i}$ actual in-plant failures. (c) Evolution of failure probability distribution. 
(a)

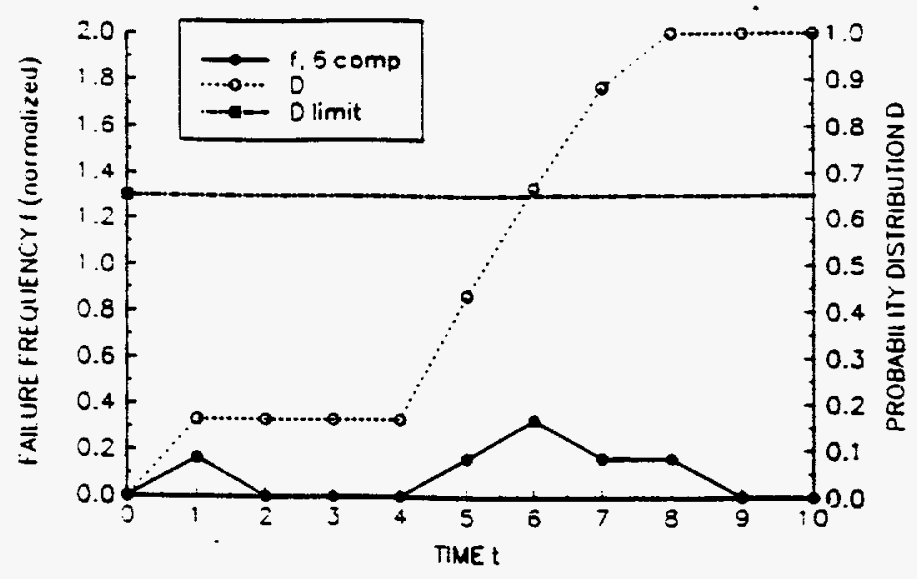

(b)

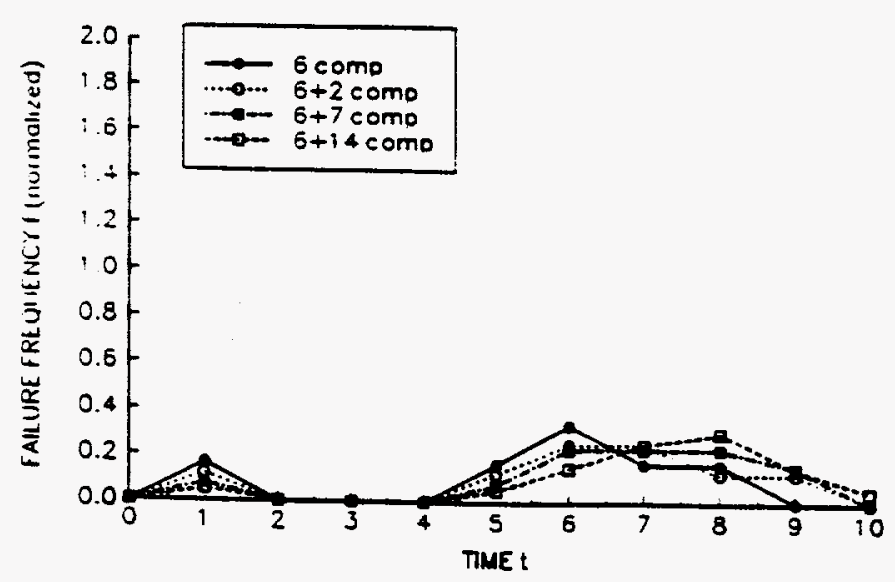

(c)

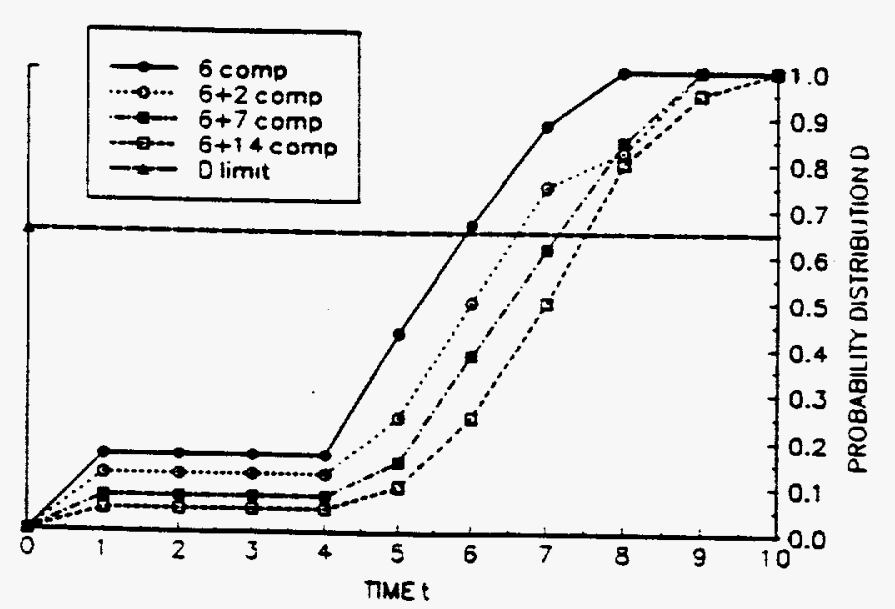

Figure C4. Failure frequency and probability distribution when meanlife of components in plant proves to be longer than expected. (a) Initial data from 6 similar components in other facilities. (b) Evolving failure frequency as in-plant components fail; " $6+i$ indicates 6 original components plus i actual in-plant failures. (c) Evolution of failure probability distribution. 


\section{C.2.2. Probabilistic Risk Analysis}

The PRA is used interactively in this methodology, and the presumption is that it is codified and implemented on a computer as a user friendly tool for systems analysis. Individual components have finite lifetimes and as they climb their probability of failure curves, they contribute progressively more to total risk. The imposed D limits (and replacement times) determine the maximum contribution to plant risk. An approach to establishing an agenda of component risk limits is to use the initial PRA to determine a preferred distribution of component limits which sums to the plant limit. This allows the facility manager flexibility to consider other factors such as component replacement cost. If components 1 and 2 contribute similar risks, but 1 costs much more than 2 , the manager may schedule a higher risk limit (and longer operating life) for 1 and a compensating lower risk for 2 . Table $\mathrm{C} 1$ summarizes a brief example of apportionment of risk limits.

Table C1. Dual PRA

\begin{tabular}{lcc}
\hline System/Components & \multicolumn{2}{c}{ Apportioned risk* limit (per year) } \\
& Safety $\left(\delta \mathrm{S}_{\mathrm{a}}\right)$ & Availability $\left(\delta \mathrm{A}_{\mathrm{a}}\right)$ \\
\cline { 2 - 3 } & & \\
Primary Coolant System & $0.6 \times 10^{-7}$ & $1.5 \times 10^{-2}$ \\
$\quad$ Component 1 & $0.4 \times 10^{-7}$ & $0.5 \times 10^{-2}$ \\
Component 2 & & \\
Control Rod System & $0.7 \times 10^{-8}$ & $2.9 \times 10^{-3}$ \\
Component 3 & $0.3 \times 10^{-8}$ & $1.1 \times 10^{-3}$ \\
Component 4 & & \\
Secondary Coolant System & $0.7 \times 10^{-8}$ & $2.9 \times 10^{-2}$ \\
Component 5 & $0.3 \times 10^{-8}$ & $1.1 \times 10^{-2}$ \\
Component 6 & $1.0 \times 10^{-8}$ & $2.4 \times 10^{-2}$ \\
Component 7 & $\mathrm{S}=1.3 \times 10^{-7}$ & $\mathrm{~A}=8.8 \times 10^{-2}$ \\
Plant total risk & & \\
\hline
\end{tabular}

"Risk definitions:

Safety (S): risk of serious accident, e.g., core damage.

Availability (A): risk of plant being unavailable when it is supposed to be available.

If a component contributes independently to risk, its failure limit $D_{a}$ associated with its apportioned risk contribution limit $\delta \mathrm{S}_{\mathrm{a}}$ is obtained by evaluating the PRA at selected points along the component $\mathrm{D}$ curve and interpolating to find $\mathrm{D}_{\mathrm{a}}$ (Figure $\mathrm{C5}$ ). This procedure can be done either interactively or by a suitable automation algorithm.

If component risks are interdependent, e.g., the risk of one is a function of whether others fail simultaneously, then risk apportionment must be made with cognizance of these dependencies to assure that maximum $S$ and $A$ are not violated by coincident failures (e.g., common cause failures). 
In the above apportionment example the conservative, simplifying assumption was made that all components may approach their risk limits at the same time, i.e. the apportionment was made on the basis of peak component risks summing to the plant $S$ and $A$ limits. More complex apportionment algorithms may take advantage of components being at relatively different points on their curves at any point in time. For instance, if a component with major replacement cost, say component 4 , is approaching its initially assigned limit, and if the plant total risks, $S$ and $A$, are currently sufficiently below limits, the facility manager may decide to raise the limit of component 4 and extend its life until total risks S and/or A reach limits, or until other relevant criterion are met. Dynamically raising component 4's limit requires

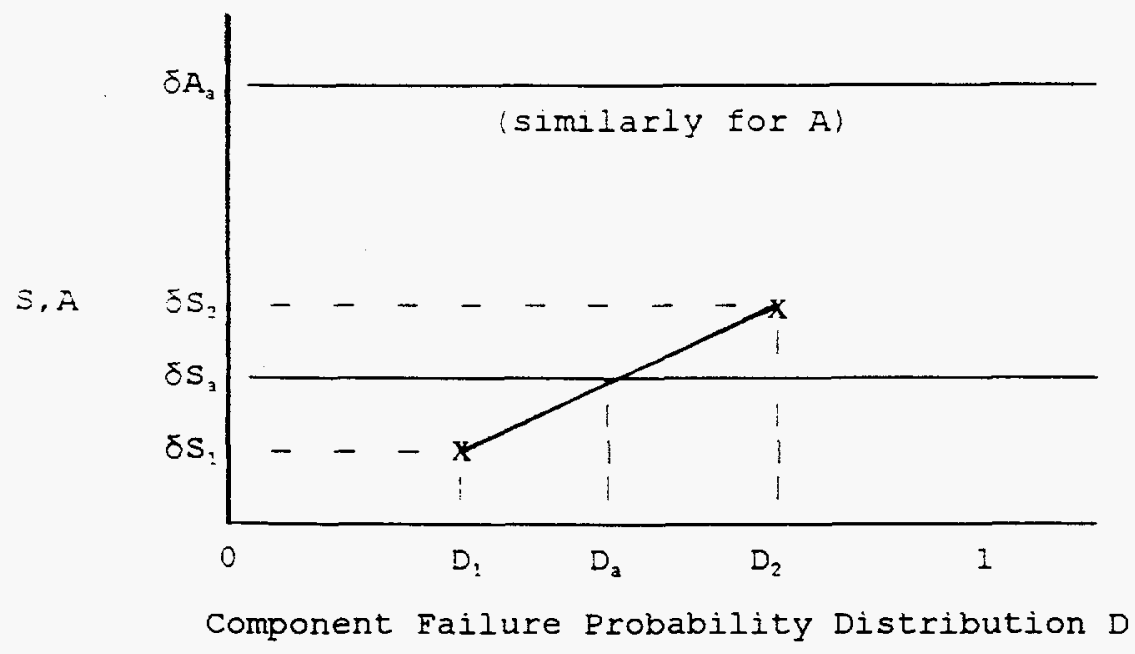

Figure $C 5$. Using PRA to find a component failure probability limit $D_{3}$.

periodically rerunning the PRA to monitor the status of S and A. Such monitoring may not be needed under the conservative assumption.

\section{C.2.3. Safety- and Availabilitv-Based Maintenance Schedule}

The preceding use of PRA analysis and failure probability curves provides safety- and availability-based times before which each component must be serviced, referred to as the "replace/do-before-date." Figure $\mathrm{C} 6$ shows the hypothetical resulting safety/availability required schedule, labeled "S/A Req," for components 1, 2 and 3 of Table 1. Time 0 is current time, so maintenance schedules march toward the left with time. The symbols $k-\#->\mid$ indicate component ID number and service time duration.

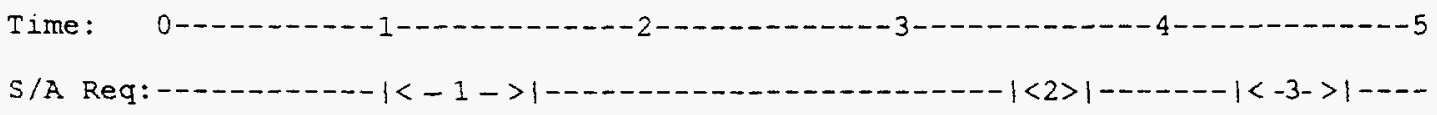

Figure C6. The required safety/availability schedule for components 1, 2 and 3. 


\section{C.2.4. Folding in User Demand; The Adaptive Maintenance Schedule}

The preceding established the times before which maintenance operations must be performed. The schedule has flexibility in that maintenance may be performed earlier in order to meet other objectives. Here the additional objective is to satisfy user demand to the extent feasible and justifiable, at the discretion of the facility manager.

The basis of folding in user demand without violating $S$ and $A$ limits is interactive use of the PRA to explore alternatives. Figure C7 is an illustration. The line labeled U-D indicates user A and B "demands" on the facility. The "S/A Req" and "U-D" schedules are in conflict.

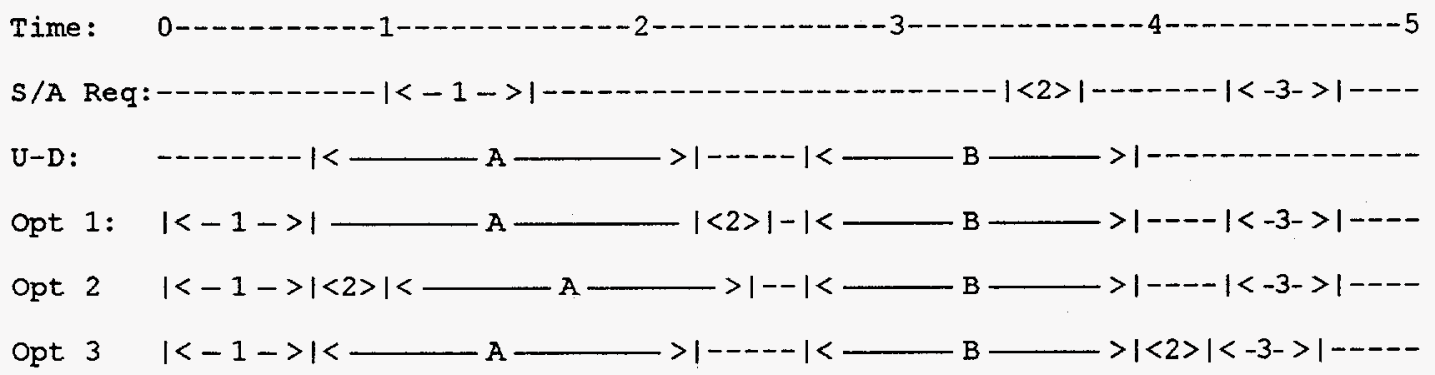

Figure C7. Development of the adaptive schedule for maintenance of components 1,2 and 3 and service of users A and B.

The three lines labeled "Opt \#" indicates options or alternative ways of blending the safety/availability/user requirements, depending upon the facility manager's definition of needs and on interactive PRA quantification of the impact of the various alternatives on the values of $S$ and $A$. In option 1 maintenance item 2 is in conflict with user $B$ and item 2 is advanced in time to fit between user $\mathrm{A}$ and $\mathrm{B}$ demands. Because new component 2 begins life on the low end of its failure probability distribution, the values of total plant safety and availability risks, $S$ and $\mathrm{A}$, should decrease.

In option 2, the facility manager decides to let user B's schedule slip slightly in order to do maintenance items 1 and 2 during a single shutdown prior to user B. Again S and A decline.

In option 3, the facility manager notes that advancing item 1 in time to place it ahead of user A inherently reduces the total S and A. Using the PRA he checks the possibility of delaying item 2 until after user B. The combination of accelerating items 1 and 2 and delaying item 3 is calculated (in the PRA) to produce net changes in S and A below the limits. Thus with Option 3 , both users are satisfied and the number of times the plant must be shut down for maintenance is reduced from 3 to 2 . This is regarded as the optimum safety/availability/userdemand maintenance schedule. 


\section{C.3. FUTURE RESEARCH}

Further research on the proposed methodology should include the use of computer simulation for a more detailed pilot study. The first major portion of this study should be implementation of a computerized PRA of an existing or proposed facility (e.g., Advanced Neutron Source reactor). PRAs are commonly part of the preliminary safety analysis of nuclear facilities and could be the basis for a computerized adaptation.

The second major portion of the study should use computer simulation to generate an operating history, component degradation and failure, and user demand for the facility to which the PRA applies.

The interactive PRA and simulated operating history would then provide the framework for investigating details of the proposed methodology and provide a firmer basis for assessing its practicality.

\section{C.4. REFERENCES}

C.1. "Long-term capital planning considering nuclear plant life-cycle management," Negin, C.A.; Simpson, J.M.; Hostetler, D.R., EPRI-TR-101162, Electric Power Research Institute, Palo Alto, Sep 1992.

C.2. "Good practices for effective maintenance to manage aging of nuclear power plants," Scott, W.B.; Enderlin, W.I.; Chockie, A.D.; Bjorkelo, K.A., Nuclear Engineering and Design, v 134:2/3, p 257-265, Netherlands, May 1992.

C.3. "An approach to aspects of aging and safety of nuclear power plants by a German expert organization," Grosserichter, R., Proceedings of the topical meeting on nuclear power plant life extension, p 571-575, American Nuclear Society, La Grange Park, IL, 1988.

C.4. "Nuclear plant aging research in the United States," Arlotto, G.; Marston, T, Proceedings of the international ENS/ANS conference on thermal reactor safety, $\vee 6$, p 2275-2288, Societe Francaise d'Energie Nucleaire, Paris, 1988.

C.5. "Identification of maintenance productivity enhancements keyed to nuclear plant performance," Hijeck, P.J.; McMullin, C.W., Trans. Am. Nucl. Soc. v 56, p 20-21, American Nuclear Society, La Grange Park, IL, 1988.

C.6. "Nuclear Plant Aging Research (NPAR) program plan," NUREG-1144-Rev.2, Nuclear Regulatory Commission, Washington, DC, Jun 1991.

C.7. "Life optimization for fossil fuel power plants," Galpin, D.S., SWEC-2596-10, CE--03750, Stone and Webster Engineering Corp., Englewood, CO, Canadian Electrical Association, Montreal, Nov 1990. 
C.8. "The relationship among reliability, aging and equipment qualification," Wanless, J.W.; Goel, V.S., Proceedings of the international conference on nuclear power plant aging, availability factor and reliability analysis, p 473-476, American Society for Metals, Metals Park, OH, 1985.

C.9. "Instrument air system-Aging impact on system availability," Villaran, M.; Subudhi, M., Transactions of the seventeenth water reactor safety information meeting, NUREG/CP-0104, p 9.3-9.4, Nuclear Regulatory Commission, Washington, DC, Oct 1989.

C.10. "Approaches for age-dependent probabilistic safety assessments with emphasis on prioritization and sensitivity studies," Vesely, W.E., NUREG/CR-5587, SAIC--92/1137, Science Applications International Corp., Dublin, $\mathrm{OH}$, Nuclear Regulatory Commission, Washington, DC, Aug 1992.

C.11. "Aging data analysis and risk assessment: Development and demonstration study," Wolford, A.J.; Atwood, C.L.; Roesener, W.S., NUREG/CR-5378, EGG--2567, EG\&G Idaho, Inc., Idaho Falls, ID, Nuclear Regulatory Commission, Washington, DC, Aug 1992.

C.12. "Incorporation of feedback of experience in probabilistic safety assessments and prospects for the development of a decision tool for maintenance," Guio, J.M. de; Zwingelstein, G., Proceedings of PSA '91: international symposium on the use of probabilistic safety assessment for operational safety, p 359-371, International Atomic Energy Agency, Vienna, 1992.

C.13. "Maintenance Management Support Systems for component aging estimation at nuclear power plants," Shimizu, Shunichi; Ando, Yasumasa; Morioka, Toshihiko; Okuzumi, Naoaki, Journal of Nuclear Science and Technology (Tokyo), v 28:11, p 1041-1057, Nov 1991.

C.14. "Evaluations of core melt frequency effects due to component aging and maintenance," Vesely, W.E.; Kurth, R.E.; Scalzo, S.M., NUREG/CR-5510, SAIC--89/1744, Nuclear Regulatory Commission, Washington, DC, Science Applications International Corp., Columbus, OH, Jun 1990.

C.15. "The use of probabilistic safety assessment in the relicensing of nuclear power plants for extended lifetimes," IAEA-TECDOC-547, International Atomic Energy Agency, Vienna, Feb 1990.

C.16. "PRAAGE-1988: An interactive IBM-PC code for aging analysis of NUREG-1150 systems," Fullwood, R.R.; Shier, W.G., Proceedings of the sixteenth water reactor safety information meeting, v 3, NUREG/CP-0097-Vol.3, p 157-173, Nuclear Regulatory Commission, Washington, DC, Mar 1989. 
C.17. "Nuclear plant aging study of residual heat removal systems," Lofaro, R.; Gunther, W.; Subudhi, M.; Taylor, J., Proceedings of the sixteenth water reactor safety information meeting, $v 3$, NUREG/CP-0097-Vol.3, p 97-107, Nuclear Regulatory Commission, Washington, DC, Mar 1989.

C.18. "UNIRAM modeling for increased nuclear-plant availability and life extension," O'Mara, R.L., Proceedings of the topical meeting on nuclear power plant life extension, p 312-317, American Nuclear Society, La Grange Park, IL, 1988.

C.19. "Component aging evaluation with expert systems," Wiesemann, J.S.; Maguire, H.T. Jr., Proceedings of the topical meeting on nuclear power plant life extension, $\mathrm{p} 511$, American Nuclear Society, La Grange Park, IL, 1988.

C.20. "Simulation of maintenance effectiveness in repairable systems to control risk due to aging," Satterwhite, D.G.; Cathey, N.G.; Meale, B.M.; MacDonald, P.E., EGG-M-88101, EG\&G Idaho, Inc., Idaho Falls, 1988.

C.21. "Explicit time-dependent analysis in Monte Carlo reliability simulations," Lewis, E.E.; Tu, Z.; Hald, U.P.; Boehm, F., Trans. Am. Nucl. Soc., v 55, p 443-444, 1987.

C.22. "A conceptual framework to analyze and mitigate aging effects of a system in nuclear power plants," Ahmed, S.; Goel, V.S., Proceedings of the international conference on nuclear power plant aging, availability factor and reliability analysis, p 99-104, American Society of Metals, Metals Park, OH, 1985.

C.23. "Using probabilistic risk assessments to rank importance of aging on nuclear power plant components," Leverenz, F.L.; Davis, T.C.; Pelto, P.J.; Goel, V.S., Proceedings of the international conference on nuclear power plant aging, availability factor and reliability analysis, p 639-642, American Society of Metals, Metals Park, OH, 1985. 
ORNL/TM-12701

\section{INTERNAL DISTRIBUTION}

1. M. A. Abdalla

2. C. W. Alexander

3. D. J. Alexander

4. R. R. Allen

5. E. E. Alston

6. J. L. Anderson

7. B. R. Appleton

8. J. G. Arterburn

9. R. E. Battle

10. R. S. Booth

11. W. W. Bowman

12. C. R. Brinkman

13. R A. Brown

14. G. J. Bunick

15-19. J. H. Campbell

20. P. F. Cento

21. N. C. J. Chen

22. K. K. Chipley

23. R. L. Clark

24. J. E. Cleaves

25. J. T. Cleveland

26. G. L. Copeland

27. J. R. Dixon

28. F. F. Dyer

29. K. Farrell

30. D. K. Felde

31. R. E. Fenstermaker

32. G. F. Flanagan

33. D. N. Fry

34. M. L. Gildner

35. H. A. Glovier

36. D. C. Haberkost

37. R. M. Harrington

38. J. B. Hayter

39. D. E. Holcomb

40. S. E. Holliman

41. M. M. Houser

42. R. O. Hussung

43. D. T. Ingersoll

44-47. R. L. Johnson

48. R. A. Kisner

49. K. Korsah
50. R. C. Kryter

51. R. A. Lillie

52. M. A. Linn

53. P. S. Litherland

54 A. T. Lucas

55. J. A. March-Leuba

56. B. S. Maxon

57. G. T. Mays

58. R. W. McClung

59. D. W. McDonald

60. S. V. McGrath

61. T. J. McManamy

62. G. R. McNutt

63. J. T. Mihalczo

64. R. M. Moon

65. D. G. Morris

66. D. L. Moses

67. J. A. Mullens

68. L. C. Oakes

69. R. E. Pawel

70. H. R. Payne

71. F. J. Peretz

72. L. D. Proctor

73. C. E. Pugh

74. C. C. Queen

75. S. Raman

76. C. T. Ramsey

77. J. S. Rayside

78. W. R. Reed

79. J. P. Renier

80. J. B. Richard

81. J. B. Roberto

82. R. E. Rothrock

83. W. J. Rowan

84. T. L. Ryan

85. J. P. Schubert

86. D. L. Selby

87. H. B. Shapira

88-92. R. L. Shepard

93. M. Siman-Tov

94. G. Slaughter

95. O. L. Smith 

96. J. O. Stiegler
97. R. P. Taleyarkhan
98. D. W. Theisen
99. P. B. Thompson
100. K. R. Thoms
101. S. R. Tompkins
102. B. R. Upadhyaya
103. B. D. Warnick
104. M. W. Wendel
105. C. D. West
106. J. L. Westbrook
107. J. D. White
108. D. L. Williams
109. D. M. Williams
110. B. A. Worley
111. G. T. Yahr
112. G. L. Yoder
113. Laboratory Records
114. Laboratory Records-RC
115. ORNL Patent Office

\section{EXTERNAL DISTRIBUTION}

116. Rod Almquist, Richland Operations Office, U.S. DOE, P.O. Box 550, Richland, WA 99352

117. R. Awan, U.S. Department of Energy, NE-473, Washington, DC 20585

118. E. P. Branagan, Jr., Office of Nuclear Safety Assessment, NE-1.2, U.S. DOE, Washington, DC 20585

119. F. Y. Chen, U.S. Department of Energy, Office of Nuclear Safety Performance Assessment, EH-11, CXXI/3, Washington, DC 20585

120. K. K. Conway, Laboratory Facilities Branch, U.S. Department of Energy, Oak Ridge Operations Office, CE-523, P. O. Box 2001, Oak Ridge, TN 37831-2001

121. R. R. Fullwood, Brookhaven National Laboratory, Upton, NY 11973

122. W. R. Gambill, Route 5, Box 220, Clinton, TN 37716

123. Jerry D. Griffith, Director, Office of Advanced Reactor Programs, Office of Nuclear Energy, NE-45, U.S. DOE, Washington, DC 20585

124. W. M. Hartman, Office of Nuclear Safety Assessment, NE-1.2, U.S. DOE, Washington, DC 20585

125. Philip B. Hemmig, Div. of Advanced Technology Development, NE-462, U.S. DOE, Washington, DC 20545

126. A. F. Henry, Professor, Department of Nuclear Engineering, Massachusetts Institute of Technology, 77 Massachusetts Avenue, Cambridge, MA 02139

127. David Howard, Director, Office of Self Assessment, DOE-OR, P.O. Box 2001, Oak Ridge, TN 38731-8600

128. R. A. Hunter, Director, Office of Facilities, Fuel Cycle, and Test Programs, Nuclear Energy Division, U.S. Department of Energy, NE-47, Washington, DC 20585

129-130. Office of Scientific and Technical Information, U.S. DOE, Bldg No. 1916-T1, P. 0. Box 62, Oak Ridge, TN 37831

131. T. L. Kerlin, University of Tennessee, College of Engineering, 315 Pasqua Engineering Building, Knoxville, TN 37996-2300

132. J. A. Lake, Manager, Nuclear Engineering and Reactor Design, Idaho National Engineering Laboratory, P. O. Box 1625, Idaho Falls, ID 83415

133. Owen W. Lowe, Office of Nuclear Safety Assessment, NE-1.2, U.S. DOE, Washington, DC 20585 
134. Steve Ludwig, Argonne Area Office, U.S. DOE, 9800 S. Cass Avenue, Argonne, IL 60439

135. Sherman Martin, Jr., DOE-OR, M/S 6269, Bldg 4500N, P.O. Box 2001, Oak Ridge, TN 38731-8600

136. J. E. Mays, Research and Test Reactor Fuel Elements, Babcock and Wilcox Co., P. O. Box 785, Lynchburg, VA 24505

137. J. P. Mulkey, U.S. Department of Energy, NE-473, Washington, DC 20585

138. W. T. Oosterhuis, Materials Sciences Division, Office of Basic Energy Sciences, Office of Energy Research, U.S. Department of Energy, ER-132, Washington, DC 20585

139. J. M. Ryskamp, Idaho National Engineering Laboratory, P. O. Box 1625, Idaho Falls, ID 83415-3885

140-154. B. H. Shapiro, Office of Nuclear Safety Assessment, NE-1.2, U.S. DOE, Washington, DC 20585

155. George Sherwood, Office of Nuclear Safety Assessment, NE-1.2, U.S. DOE, Washington, DC 20585

156. J. L. Snelgrove, Coordinator, Engineering Applications, RERTR Program, Argonne National Laboratory, 9700 South Cass Avenue, Argonne, IL 60439

157. I. Thomas, Acting Associate Director, Materials Science Division, Office of Energy Research, U.S. Department of Energy, ER-13, Washington, D.C. 20585

158. U. S. Department of Energy, ANS Project Office, Oak Ridge Operations Office, FEDC, MS-8218, P. O. Box 2009, Oak Ridge, TN 37831-8218

159. H. G. Wood, III, Associate Professor, Department of Mechanical and Aerospace Engineering, Thornton Hall, University of Virginia, Charlottesville, VA 22901

160. Office of Assistant Manager for Research and Development, DOE-ORO, P.O. Box 2008, Oak Ridge, TN 37831-6269 